\title{
Parametric Assessment of Stress Development and Cracking in Internally Cured Restrained Mortars Experiencing Autogenous Deformations and Thermal Loading
}

\author{
Kambiz Raouf,, ${ }^{1}$ John Schlitter, ${ }^{1}$ Dale Bentz, ${ }^{2}$ and Jason Weiss ${ }^{1}$ \\ ${ }^{1}$ School of Civil Engineering, Purdue University, 550 Stadium Mall Drive, West Lafayette, IN 47907, USA \\ ${ }^{2}$ Engineering Laboratory, National Institute of Standards and Technology, 100 Bureau Drive, Stop 7313, \\ Gaithersburg, MD 20899, USA
}

Correspondence should be addressed to Kambiz Raoufi, kamraoufi@gmail.com

Received 22 January 2011; Accepted 26 May 2011

Academic Editor: Kent A. Harries

Copyright () 2011 Kambiz Raoufi et al. This is an open access article distributed under the Creative Commons Attribution License, which permits unrestricted use, distribution, and reproduction in any medium, provided the original work is properly cited.

\begin{abstract}
A finite element model is used to examine how the properties of cementitious mortar are related to the stress development in the dual ring test. The results of this investigation are used to explain the thermal cracking behavior of mixtures containing prewetted lightweight aggregates (LWA) by quantifying the contribution of several material properties individually. In addition to the beneficial effects of using the LWA as an internal curing agent to reduce the autogenous shrinkage of concrete, the LWA also helps to reduce the potential for thermal cracking due to a lower elastic modulus and increased stress relaxation. The rate of stress development, age of cracking, and magnitude of the temperature drop necessary to induce cracking in a dual ring specimen are dependent on a variety of factors, including the coefficient of thermal expansion of both the cementitious mortar and the restraining rings, elastic modulus of the mortar, creep effect of the mortar, and rate of thermal loading. Depending on the rate of cooling, cracking may or may not occur. The slowest rate of cooling $\left(2.5^{\circ} \mathrm{C} / \mathrm{h}\right)$ minimizes the effects of creep while cooling rates faster than $8^{\circ} \mathrm{C} / \mathrm{h}$ can produce a thermal gradient through the mortar cross-section that needs to be considered.
\end{abstract}

\section{Introduction}

When volume changes caused by the heating or cooling of concrete are restrained, residual tensile stresses can develop $[1,2]$. These residual stresses can result in cracking if they reach the tensile strength of the concrete. The potential for cracking depends on a combination of a variety of factors including the degree of restraint in the concrete [3], the early-age mechanical property development of concrete [4], the shrinkage of concrete [5], the thermal properties of the concrete (e.g., coefficient of thermal expansion and heat capacity) [6], the heat of hydration [6], the rate of temperature change in concrete [7], and the environmental conditions such as ambient temperature and wind speed [8].

The dual ring test has previously been used to study the stress development and cracking behavior of concrete materials that show shrinkage or expansion at early ages [9-11]. The dual ring test consists of a mortar or concrete specimen that is cast between two concentric restraining rings. If materials for restraining rings are not selected properly in the dual ring test, temperature changes can substantially move the restraint boundaries and alter the degree of restraint. As such, the restraining rings in tests considered in this paper are constructed from Invar 36, a metal alloy having a minimal coefficient of thermal expansion [12-14] (Certain commercial equipment, instruments, or materials are identified in this report in order to foster understanding. Such identification is not intended to imply recommendation or endorsement by the National Institute of Standards and Technology nor Purdue University, nor is it intended to imply that the materials or equipment identified are necessarily the best available for the purpose.). When concrete expands, its expansion is restrained by both the inner and outer Invar rings and a compressive stress is developed in the concrete specimen in the circumferential direction. When the concrete shrinks, it is restrained by the inner Invar ring and tensile stresses develop in the concrete in the circumferential direction. The cracking potential of 
concrete increases significantly once the residual tensile stress approaches the tensile strength of concrete $[5,15]$.

Previously, researchers have used the dual ring test to study the early-age cracking behavior of a cement paste containing a shrinkage-reducing admixture and a cement paste containing an expansive admixture $[11,16,17]$. Bentz et al. [10] used the dual ring to illustrate the influence of cement fineness on restrained shrinkage cracking of hydrating cement paste. Kim et al. [18] have extended the use of a dual ring geometry to study the low-temperature cracking performance of asphalt concrete mixtures. Schlitter et al. [9] used a temperature drop approach to study the thermal cracking of concrete and showed that using prewetted LWA is beneficial in improving the thermal cracking resistance of concrete. In this approach, the dual ring geometry was maintained at a constant room temperature for a specific time period; if cracking did not occur at this point, the temperature was reduced to induce cracking. Schlitter et al. [9] further used the dual ring geometry to characterize earlyage expansion behavior and shrinkage cracking performance of concrete containing super absorbent polymers [19].

Restrained thermal and autogenous shrinkage are known as two of the primary contributions to the potential for cracking in concrete members at early ages [2]. Autogenous shrinkage stresses and thermally induced residual stresses can be approximated as being additive [4]. As such, an increase in the magnitude of the shrinkage of concrete makes the concrete more susceptible to thermal-induced cracking. Recently, the use of the prewetted LWA has been advocated as a method to reduce autogenous shrinkage. The prewetted lightweight aggregate serves to increase relative humidity inside the concrete, thereby reducing capillary tension and the associated residual stress development in concrete [20, 21]. Shin et al. [22] have also shown that the use of aggregates with reduced stiffness can improve the shrinkage cracking resistance of concrete due to the combined effects of a lower elastic modulus and higher stress relaxation.

This paper describes the use of finite element simulations to quantify the influence of several material properties on the rate of thermal stress development and cracking potential in the dual ring test. The information from this study will be used to refine how the results of the dual ring test are interpreted, to refine the testing geometry and to assess how the test should be used in specifications. Further, the impacts of using prewetted LWA on improving the thermal cracking performance of concrete are discussed.

\section{Modeling Approach}

Commercial finite element software, FEMMASSE HEAT MLS 8.5, was used to model stress development and cracking in the dual ring test. The finite element model enables stresses, displacements, temperature profile, and cracking to be determined throughout the dual ring geometry. A dual ring geometry, similar to the geometry used by Schlitter et al. [9], was modeled in this study. The geometry consisted of an aging cementitious mortar/concrete annulus that was cast between two concentric Invar rings. The mortar was treated

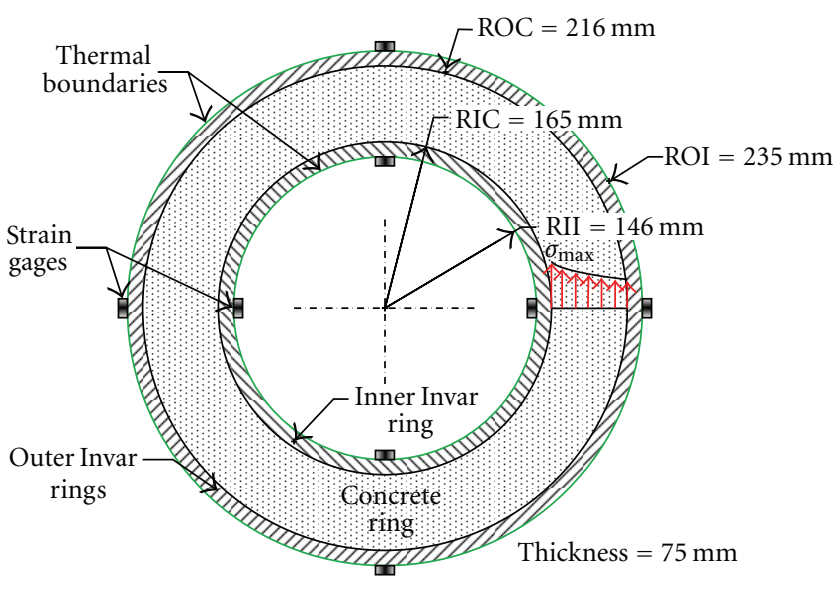

FIgURE 1: Schematic overview of the finite element model.

as an aging viscoelastic material, with a cohesive fracture behavior. Age-dependent tensile strength, elastic modulus, $\sigma$ $w$ curves (i.e., fracture properties), and autogenous shrinkage were measured separately [23] and used to simulate the mortar/concrete specimen. The approach introduced by Schlitter et al. [9] used cooling at different ages to determine the reserve stress capacity. Time-dependent temperature boundary conditions were used to reduce the temperature of the specimen. Further details on the modeling approach can be found elsewhere $[24,25]$.

The stress development and cracking in the model were compared and calibrated with a similar dual ring experiment [23]. A close agreement was observed between the stress development and cracking in the model and the experiment. The model was then used to perform a sensitivity analysis. The magnitudes of input elastic modulus, the coefficient of thermal expansion, rate of cooling, stress relaxation, autogenous shrinkage, and heat capacity could be varied independently in the model so that the impact of each input property on the stress development and cracking could be determined. The results of the sensitivity analysis were used to explain the influence of prewetted lightweight aggregate on the thermal stress development and cracking of concrete specimens.

\subsection{A Description of the Modeling Approach. Figure 1 shows} the geometry of the two-dimensional finite element model that was used in this study. The geometry consisted of a mortar/concrete annulus located between two concentric Invar rings. It should be noted that since the geometry of the mortar/concrete specimen is similar to that of the ASTM C1581-09a restrained ring specimen [26], the degree of restraint would be the same [26]. Additional details on how this geometry was developed are given elsewhere $[9,27]$.

Plane stress conditions were assumed. Quadrilateral four-node elements were used in the simulations. The mortar/concrete and Invar rings were all modeled as individual bodies. A series of frictionless cohesionless interface elements were used to model possible separations of the materials at their interface. This is similar to the conditions existing in dual ring experiments [9]. 
The Invar rings were assumed to remain in their elastic region. A Rankine fracture criterion was used to model the formation of a crack in the concrete (i.e., cracking started when the maximum principal stress reached the strength of the concrete). A cohesive zone model [28] was used to describe the postpeak stress-crack opening behavior in the concrete once the crack formed. To ensure similar crack locations between different simulations, better interpret the results, and increase numerical accuracy, the strength of a sixdegree section of the concrete ring (i.e., like a slice of a pie) was reduced by $10 \%$. The crack propagated normal to the direction of maximum principal stress which was consistent with the mesh orientation. A refined mesh was then used in the six-degree concrete ring section to increase numerical accuracy.

No moisture exchange was allowed from the concrete to its surrounding environment. The temperatures at the inner surface of the inner Invar ring and the outer surface of the outer Invar ring were prescribed by a defined temperature function. It should be noted that in contrast to conventional convective boundary conditions, the heat transfer coefficient was not considered in this case and the temperature of materials at the boundary was instead defined by the prescribed temperature functions. The temperature of the specimen was maintained at $23^{\circ} \mathrm{C}$ until the cooling was applied after $48 \mathrm{~h}$ from the time of casting at a constant rate of $2.5^{\circ} \mathrm{C} / \mathrm{h}$ (for the baseline case). This procedure is similar to the temperature drop approach that is discussed in [9].

It is worth mentioning that when shrinkage (due to autogenous shrinkage or temperature reduction) of a ring specimen is restrained by an inner ring, tensile stresses develop in the concrete specimen. The maximum tensile stress due to autogenous shrinkage occurs in the circumferential direction at the interface between the specimen and the inner restraining ring (as shown in Figure 1). Neglecting any creep effect of the concrete and assuming elastic material behavior, the stress development in the specimen is dependent on both the stiffness and the geometry of the concrete and restraining rings and would decrease as a function of the inverse of the square of the ring radius [29]. Since the concrete is an aging viscoelastic material, the stress relaxation that occurs in the concrete reduces the residual stress development. The magnitude of the stress relaxation depends on the age of concrete, the rate of stress development, the stress level, the duration of loading, the moisture content, and the mechanical properties of concrete.

2.2. Input Material Properties. The properties used in this study were chosen to represent five mortar mixtures which had a water-to-cement ratio by mass $(w / c)$ of 0.30 and $55 \%$ fine aggregate by volume [23]. Two different types of prewetted LWA were used in [23] and are designated by LWAK and LWAH in this paper. The mortar mixtures are designated as LWA-0, LWAK-8, LWAK-16, LWAH-12, and LWAH-24 in this paper. LWA-0 represents the plain mortar mixture, while LWAK-8 and LWAK-16 mixtures had 8.25\% and $16.5 \%$ of their total volume replaced with the prewetted LWAK aggregates, respectively. Similarly, LWAH-12 and

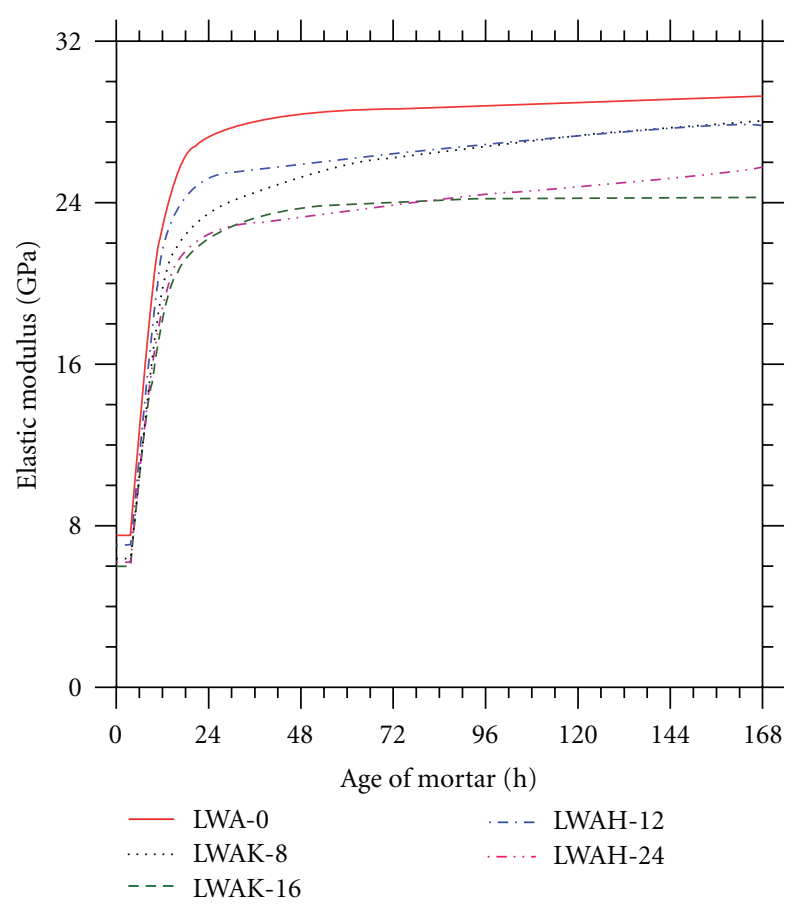

FIGURE 2: Elastic modulus development of mortar mixtures (fitted) [23].

LWAH-24 had $11.85 \%$ and $23.7 \%$ of their total volume replaced with the prewetted LWAH aggregates. It should be mentioned that these LWAK and LWAH aggregates have different water absorption capacities ( $24 \mathrm{~h}$ water absorption of $15.6 \%$ for LWAK and $10.5 \%$ for LWAH). As such, $16.5 \%$ or $23.7 \%$ volumes of LWAK or LWAH in these mortar mixtures provide the same volume of internal curing water and this volume compensates for the chemical shrinkage in these mixtures [20,23].

Cylindrical specimens $(100 \mathrm{~mm} \times 200 \mathrm{~mm})$ were cast according to ASTM C192 and tested to determine the mechanical properties of the mortar mixtures at $1 \mathrm{~d}, 3 \mathrm{~d}$, and $7 \mathrm{~d}$ from the time of casting. It should be noted that all cylindrical specimens were demolded after $24 \mathrm{~h}$ and were immediately sealed in plastic bags to prevent water loss. The splitting tensile strength was determined using ASTM C 49604 [30], while the static elastic modulus was determined according to ASTM C 469-02 [31]. The corrugated tube protocol [32] was used to measure the early age autogenous deformations of the mortar mixtures, and ASTM C 403-08 [33] was followed to determine time zero (taken as the time of final set) in this analysis. These material properties were fitted using commercial automated curve fitting software [34], and were used as input values to simulate the mortar behavior at early ages. Figures 2, 3, and 4 summarize these input material properties. It can be seen in Figures 2 and 3 that the elastic modulus and tensile strength of the mortar decreased as the volume replacement of the prewetted LWA in the mortar increased. Further details on mixture proportions, testing procedures, and measuring material properties can be found in [23]. 


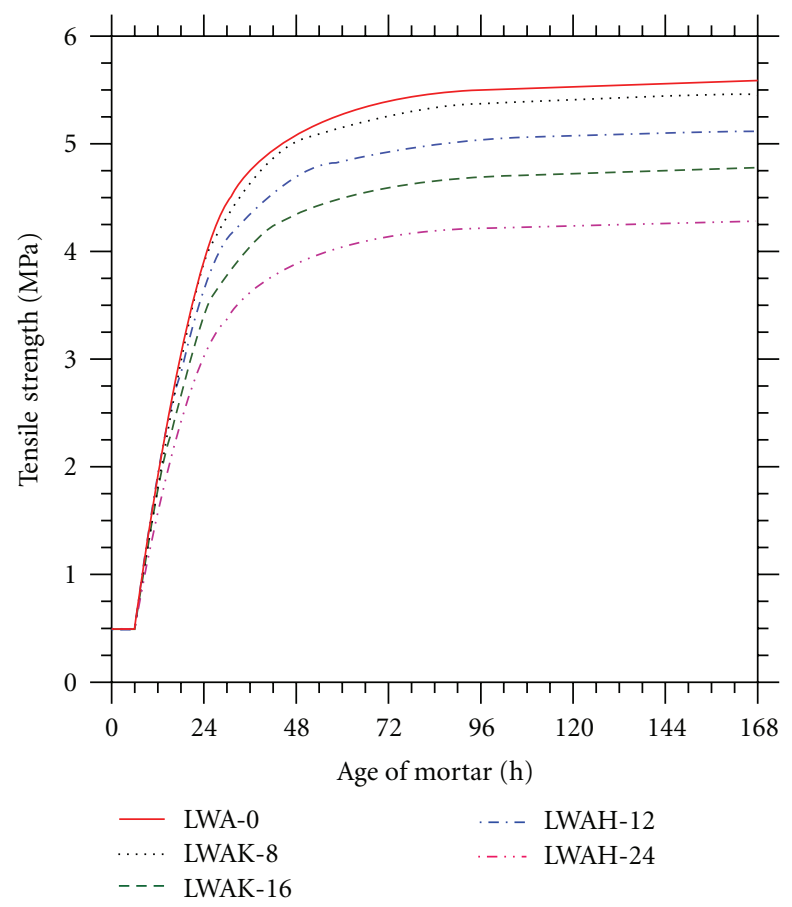

Figure 3: Tensile strength development of mortar mixtures (fitted) [23].

To determine the coefficient of thermal expansion (COTE) for the specimens, two mortar prisms $(25 \mathrm{~mm} \times$ $25 \mathrm{~mm} \times 285 \mathrm{~mm}$ ) were cast for each mortar mixture. The prisms were prepared according to ASTM C490-09 [35]. All prisms were demolded after $24 \mathrm{~h}$. They were immediately sealed using aluminum tape after demolding to prevent water loss and cured at $23^{\circ} \mathrm{C}$ for seven days. As specified by ASTM C490-09 [35], a digital dial gage with a precision of $0.001 \mathrm{~mm}$ was used to measure the length of specimens. The temperature of the specimens was changed from $23^{\circ} \mathrm{C}$ to $10^{\circ} \mathrm{C}$ and the length was measured after $24 \mathrm{~h}$. The temperature was then changed to $38^{\circ} \mathrm{C}$ and the length of the specimens was determined after another $24 \mathrm{~h}$. The lengths of the specimens at $10^{\circ} \mathrm{C}, 23^{\circ} \mathrm{C}$, and $38^{\circ} \mathrm{C}$ were used to determine the COTE. Measurements indicated that all mortar mixtures had a similar COTE, and the COTE of these mixtures did not appear to be statistically sensitive to the presence of the LWAs that were used in this study [36-38]. Based on these experiments, an average COTE value of $14 \mu \varepsilon /{ }^{\circ} \mathrm{C}$ was used to model thermal deformations of the mortar mixtures in the simulations. It should be noted that while the actual COTE of mortar may not be constant over a wide temperature range, for simplicity and the relatively small temperature difference discussed in this paper, a constant COTE was assumed.

Thermal conductivity of concrete is greatly dependent on the density, moisture content, and microstructural characteristics of concrete [36]. However, the influence of thermal conductivity is not significant in relatively thin concrete geometries such as the dual ring specimen. For simplicity reasons, a constant volumetric heat capacity of

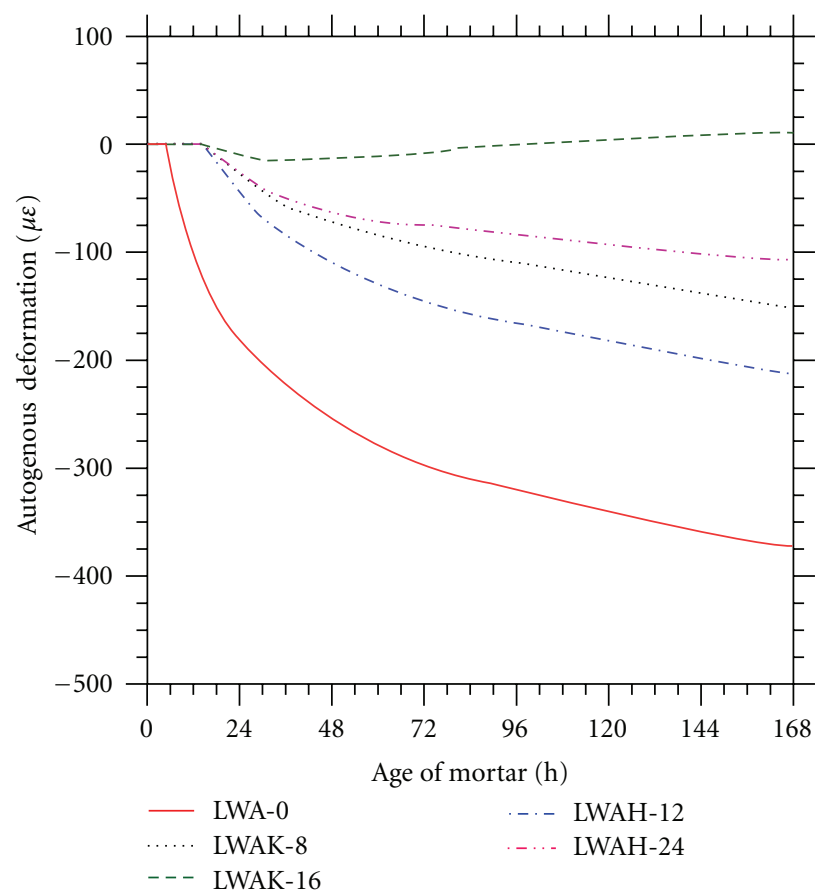

FIGURE 4: Fitted autogenous shrinkage development of plain mortar and mortars with the prewetted LWAs [23].

$2100 \mathrm{~kJ} /\left(\mathrm{m}^{3} \cdot \mathrm{K}\right)[9]$ and a constant thermal conductivity of $1.8 \mathrm{~W} /(\mathrm{m} \cdot \mathrm{K})$ [39] were used to characterize the thermophysical properties of the mortar specimens. A wedge splitting test was performed according to the procedure outlined in [40] to determine fracture properties of these mixtures. It was determined that these mixtures had a similar shape for their softening curves, and a bilinear softening curve was used to characterize the post-peak behavior of these materials in this investigation. The softening relationship was characterized by a knee point with a stress-to-strength ratio of 0.35 and a crack width of $0.01 \mathrm{~mm}$, and a critical crack width of $0.08 \mathrm{~mm}$.

An age-dependent Maxwell chain model with four Maxwell elements was used to model stress relaxation and creep [41]. The fourth unit in the Maxwell Chain Model consisted of a spring to better model the aging viscoelastic behavior of the specimen [25]. The coefficients of the Maxwell Chain Model captured the aging creep characteristics of concrete. To estimate the coefficients of the Maxwell Chain Model, the stress development in the model was compared with the stress development in a dual ring experiment [23]. The age-dependent coefficients of the Maxwell units were fitted at various ages to yield a similar residual stress development in the dual ring model and the experiment. The coefficients of the Maxwell units can be found in [24].

Invar rings were assumed to have a constant elastic modulus of $141 \mathrm{GPa}$, a constant Poisson's ratio of 0.30 , and a constant COTE of $1.30 \mu \varepsilon /{ }^{\circ} \mathrm{C}[9,12,13]$. 


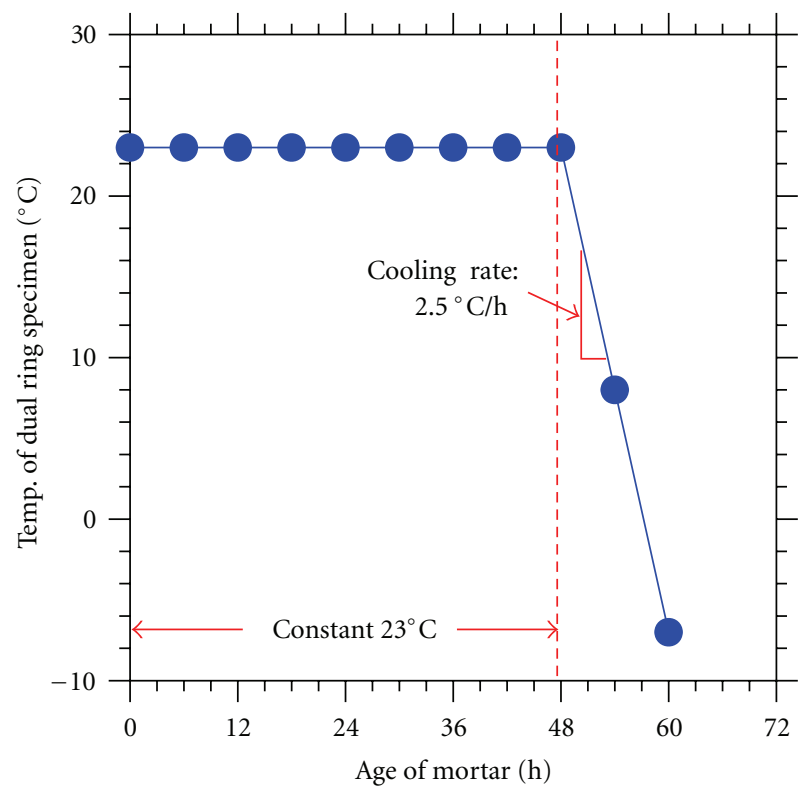

(a)

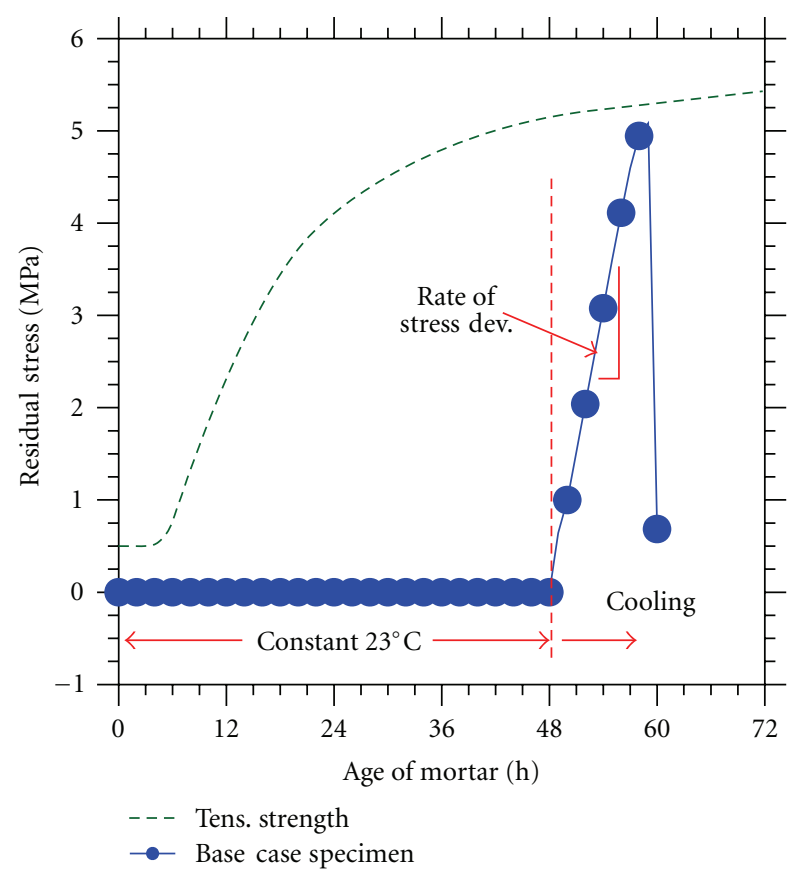

(b)

FIGURE 5: (a) Temperature profile and (b) average residual stress development in base case specimen when cooled at $48 \mathrm{~h}$.

\section{Thermal Cracking in Dual Ring Specimens}

Schlitter et al. [9] used the dual ring test to study the cracking behavior of concrete mixtures that experience earlyage autogenous shrinkage or expansion while undergoing temperature changes. The rings were initially cured at constant temperature of $23^{\circ} \mathrm{C}$. At a specific predetermined age, the specimens were cooled at a constant rate of $2.5^{\circ} \mathrm{C} / \mathrm{h}$ until the specimen cracked or the lower temperature limit of the experimental setup was reached. The magnitude of the temperature drop was used to quantify the thermal cracking resistance of a concrete mixture at that age.

A similar procedure was used in this study, as illustrated in Figure 5. The specimen was initially maintained at a constant temperature of $23^{\circ} \mathrm{C}$ for the first $48 \mathrm{~h}$. During this time period, no stress was developed in the specimen other than autogenous shrinkage-induced stress (which was assumed to be zero for the base case model shown in Figure 5). Cooling of the specimen began at $48 \mathrm{~h}$ at the rate of $2.5^{\circ} \mathrm{C} / \mathrm{h}$ (Figure $5(\mathrm{a})$ ). When the cooling began, thermal deformations were restrained by the inner Invar ring, resulting in the development of tensile stresses in the specimen. A small temperature difference of $0.3^{\circ} \mathrm{C}$ was observed in both physical experiments and FEM simulation between the outside specimen circumference at the radius of $215 \mathrm{~mm}$ and the center of the specimen at the radius of $190 \mathrm{~mm}$ during the cooling phase. As such, the temperature distribution can be assumed to be uniform through the concrete section. The simulated strength development and the average tensile stress (i.e., average stress along the radial direction) in the concrete specimen are illustrated in Figure 5(b). It should be noted that the average tensile stress values in this study were calculated as the average of circumferential stress values at 10 equi-distance locations along the radial direction of the concrete specimen and outside of the reduced strength zone [5]. Once the cooling started at $48 \mathrm{~h}$, the rate of stress development increased to $0.45 \mathrm{MPa} / \mathrm{h}$. Cracking occurred once the calculated average stress approached the tensile strength and reached a peak stress value. The peak average stress value is referred to as the failure stress in this paper. Cracking of the ring specimen is marked by a sharp drop in the average stress curve as illustrated in Figure 5(b). In the base case simulation, cracking occurred $11 \mathrm{~h}$ after the cooling began, at which time the temperature of the specimen was $-4.5^{\circ} \mathrm{C}$. This corresponded to a temperature drop of $18.5^{\circ} \mathrm{C}$ (i.e., $23^{\circ} \mathrm{C}-$ $4.5^{\circ} \mathrm{C}=18.5^{\circ} \mathrm{C}$ ). It should be noted that the "base case" model described in this work is only used for performing the parametric study and does not represent a real control specimen, since a real control plain mortar specimen could experience autogenous shrinkage during the first $48 \mathrm{~h}$.

To better explain the cracking behavior and stress development in the dual ring specimen, the crack opening displacement (COD) and stress distribution in the reduced strength region of the reference (base case) ring specimen are shown in Figure 6. It should be noted that the COD is a defined fracture mechanics term that describes crack opening at the tip of a propagating crack and, therefore, it differs from the crack width term that is conventionally used in literature. It can be seen that the stress reached the strength of the concrete at the inner circumference of the specimen and cracking initiated at $55 \mathrm{~h}$. The length of the crack can be determined by locating the maximum stress value at each time and its distance from the inner surface of 


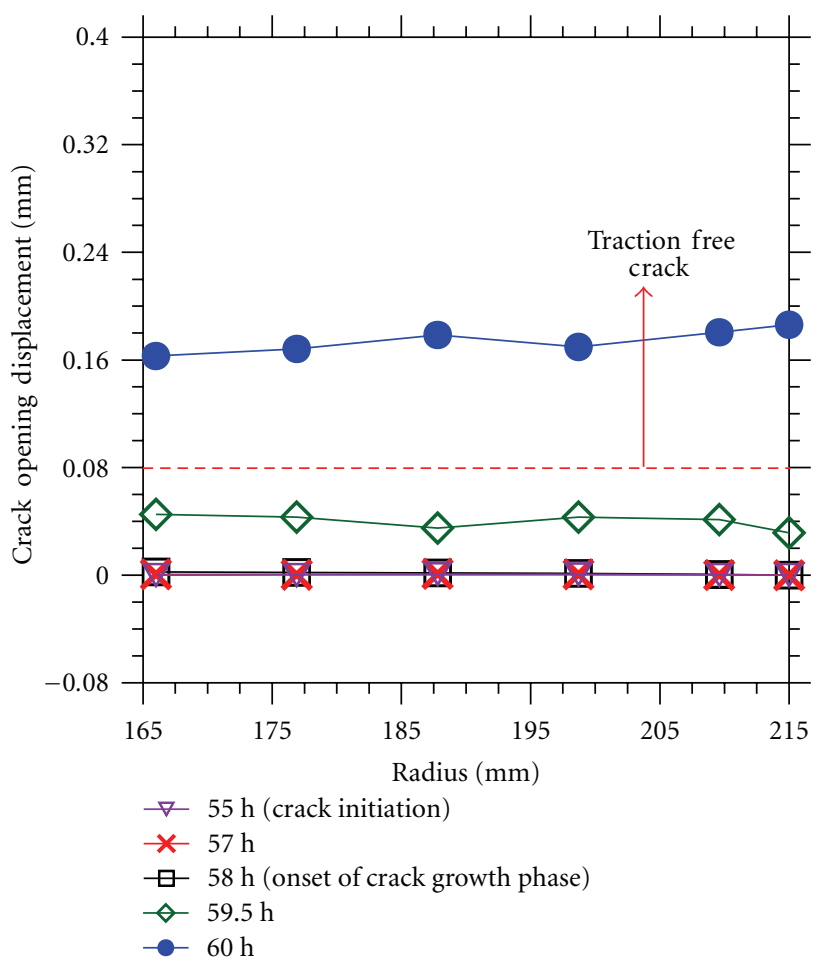

(a)

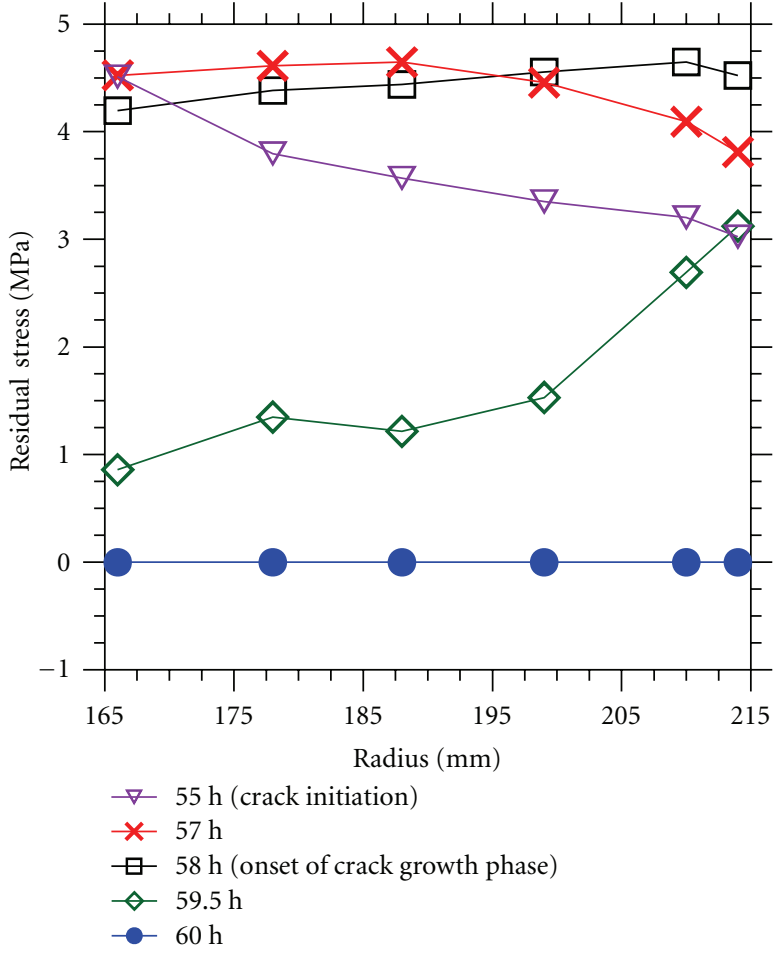

(b)

FIGURE 6: (a) Crack opening displacement and (b) average residual stress profile in the reduced strength section of the base case ring specimen when cooled at $48 \mathrm{~h}$.

the ring. The crack propagated in a stable fashion between $55 \mathrm{~h}$ and $58 \mathrm{~h}$. During this same time period, the length of the crack grew to $45 \mathrm{~mm}$ through the concrete section, which is $50 \mathrm{~mm}$ thick. The average section stress increased while a small crack opening displacement was observed. At $58 \mathrm{~h}$, the crack propagation phase began. During this phase, the crack opening displacement began to increase at a faster rate and stresses began to decrease through the mortar wall. Once the crack opening displacement exceeded the critical crack width of $0.08 \mathrm{~mm}$ at $60 \mathrm{~h}$, the crack became traction free and the specimen began to deform freely. For the age of 60 hours, the information in Figure 6(b) should be considered as illustrative rather than exact due to large sudden deformations and model instability at the time of concrete failure at $60 \mathrm{~h}$.

Figure 7 compares calculated stresses in the plain mortar specimen and the specimens containing different volumes and types of the prewetted LWA. Figure 7 shows that each mortar specimen experienced a different rate and magnitude of stress development after the time of set. The differences in the rate of stress development can be attributed to different age-dependent mortar elastic modulus (Figure 2), stress relaxation, and autogenous shrinkage development in these mixtures (Figure 4). For example, the plain mortar specimen (LWA-0) had the highest elastic modulus and autogenous shrinkage, which lead to the highest rate and magnitude of stress development. On the other hand, the LWAK16 specimen developed a compressive stress at early ages due to its early-age autogenous expansion (Figure 4). The cooling began at $48 \mathrm{~h}$ in all cases. After the cooling began, thermal stresses began to be superimposed on the already developing shrinkage stresses and the differences in rate of stress development were further magnified. This behavior is consistent with experimental observations as reported by Schlitter et al. [27]. Consequently, several additional factors such as the coefficient of thermal expansion, rate of heating, heat capacity, and thermal conductivity can further influence the stress development in these materials. This research is aimed at quantifying the individual influences of each of these factors on the stress development and cracking behavior in the dual ring specimen test.

\section{Sensitivity Analysis}

To determine the sensitivity of the dual ring test to different testing conditions and material properties, seven series of simulations were performed. Only one factor was varied in each series, while all other mixture properties were kept the same as those of the plain mortar mixture. This allowed the influence of each factor on the rate of stress development, failure stress, the age of cracking, and the thermal resistance of the dual ring specimen to be determined. The simulations and results are summarized in Table 1. As shown in Table 1, the influence of the concrete's elastic modulus, the COTE of mortar mixtures, the COTE of the metal rings, the rate of cooling, the stress relaxation of concrete, the autogenous 


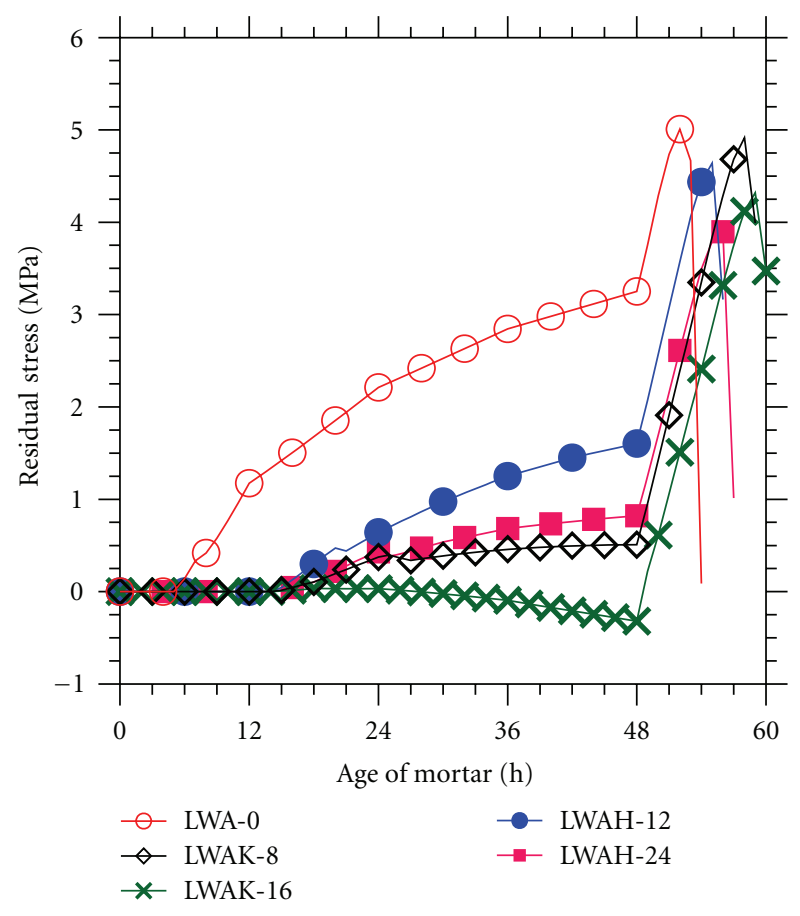

Figure 7: Calculated residual stress development in dual ring specimens when cooling began after $48 \mathrm{~h}$.

shrinkage of concrete, and the concrete's volumetric heat capacity on stress development and cracking behavior were investigated in this sensitivity analysis. The bold numbers in Table 1 indicate cases where the rate of stress development and the magnitude of the temperature drop to induce cracking were highly sensitive to changes in a particular variable. These simulations are discussed in the following sections. Since the equations underlying the FEMMASSE model do not contain many cross-product terms that are based on the input parameters, as expected, no significant effects on the rate of stress development were found when multiple factors were varied at the same time (i.e., two factor interactions were determined to be negligible).

4.1. Influence of Elastic Modulus. Adding prewetted lightweight aggregate to the mortar influences its elastic modulus in two ways. First, the addition of the lower stiffness lightweight aggregate reduces the elastic modulus of the composite [22, 42]. Second, the internal curing water stored inside lightweight aggregates increases the cement hydration and thereby increases the elastic modulus of the matrix accordingly [43]. The net effect is generally a reduction in elastic modulus as shown in Figure 2 [23]. To determine the role of elastic modulus on the stress development and cracking in the dual ring specimen, six simulations were performed. The elastic modulus of plain mortar was altered by $\pm 20 \%, \pm 40 \%$, and $\pm 60 \%$ in these simulations while all other mortar properties were held the same as that of the base case specimen (Table 1).

Figure 8(a) shows the influence of elastic modulus on the rate of stress development in the dual ring specimen.
In the absence of shrinkage deformation, no residual stress was developed before the cooling began and stresses were developed starting at $48 \mathrm{~h}$. Figure 8 (a) shows that increasing the mortar elastic modulus increased the rate of stress development, and the specimen cracked earlier. When the mortar elastic modulus was reduced to $40 \%$ of its initial magnitude, stresses developed at a rate of $0.25 \mathrm{MPa} / \mathrm{h}$ while stresses developed at a rate of $0.69 \mathrm{MPa} / \mathrm{h}$ when the elastic modulus was increased to $160 \%$ of its baseline value. It should be noted that three phenomena occurred when reducing the elastic modulus of the mortar specimen. First, the degree of restraint of the dual ring test increased with a reduction in the mortar elastic modulus $[5,44]$. Increasing the degree of restraint acts to increase the stress developed for a given strain value. However, the second effect involves a direct reduction of stress development in the specimen for a given strain due to Hooke's Law. The third effect, which was less significant than the other two effects, included an increase in stress relaxation with reducing the elastic modulus. The second effect has a greater influence on stress development; therefore, the observed rate of stress development decreased with a reduction in the elastic modulus of the mortar specimen.

The effects of specimen elastic modulus on the magnitude of the temperature drop required to induce cracking and on the average section stress of the specimen at failure are shown in Figure $8(\mathrm{~b})$. As the elastic modulus was reduced, stresses developed more slowly and a larger temperature drop was needed to crack the specimen. It should be noted that the magnitude of the required temperature drop started to increase at a greater rate as the mortar elastic modulus fell below $80 \%$ of the plain mortar elastic modulus. This behavior can be attributed to greater stress relaxation and creep in mortar specimens with lower elastic modulus values. It should be noted that the stress relaxation was increased when the specimen cracked at a later age.

Figure 8(b) shows that the average stress of the specimen at failure was reduced with an increasing elastic modulus. To explain the influence of elastic modulus on the failure stress and stress distribution in the specimen, the stress distribution and crack opening displacement through the wall of the concrete ring are shown in Figure 9 during the stable and unstable crack propagations. It can be seen in Figure 9 that considerable crack opening and unloading began to occur in the cracked region as the crack grew in size. The unloading and crack opening were more significant in the specimens with reduced elastic modulus (Figure 9) than in the base case (Figure 6). The greater unloading of the cracked specimen can be explained by the existence of a more compliant crack in specimens with a lower elastic modulus. As the elastic modulus of the specimen was reduced, its stiffness was reduced, crack opening displacement increased, and stress transfer and softening through surfaces of a crack were reduced. As such, the failure stress (average section stress at the onset of unstable cracking) was reduced with decreasing elastic modulus. Due to the additional effect of stress relaxation, the effect of elastic modulus on reducing the average stress at failure of the specimen became more 


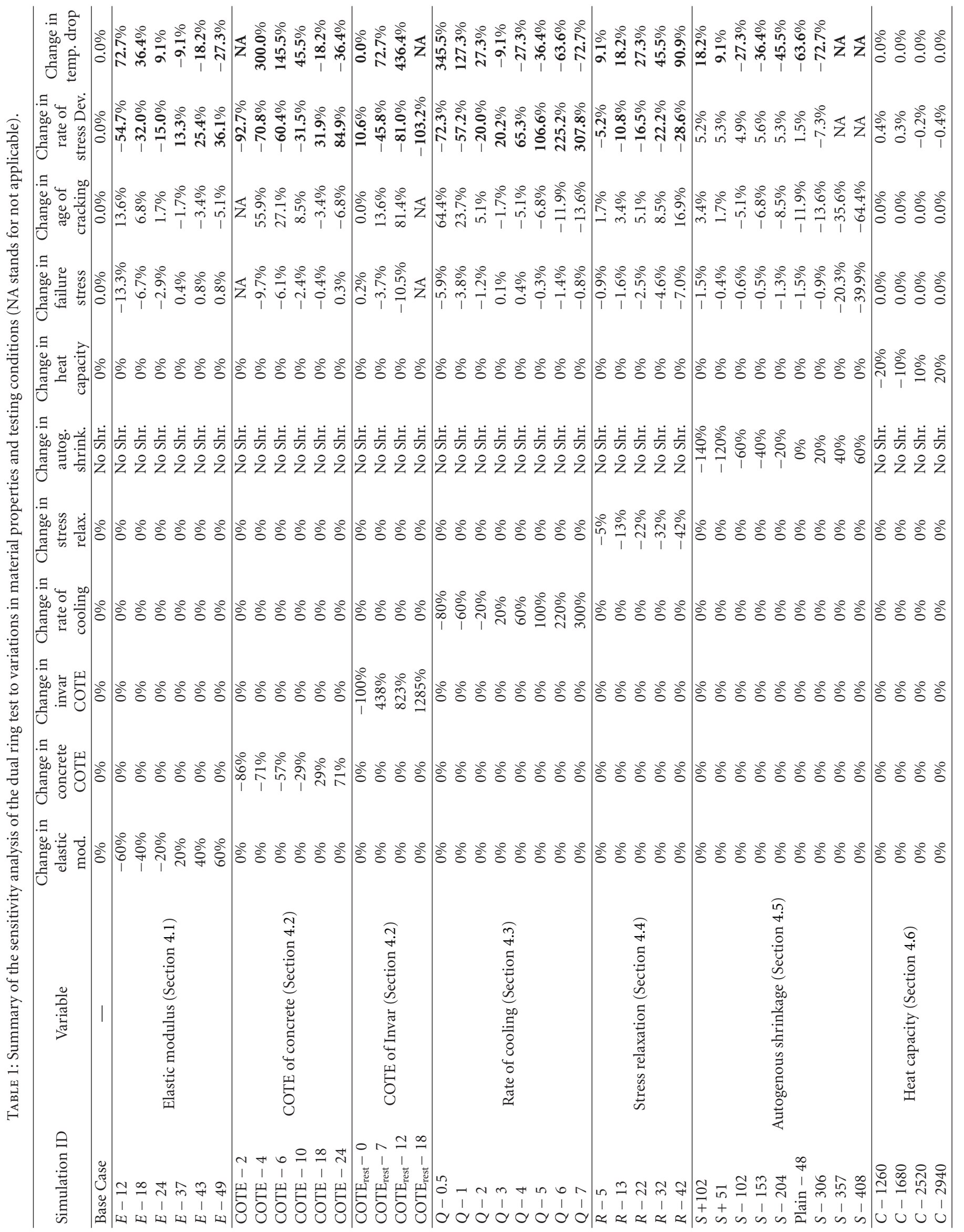




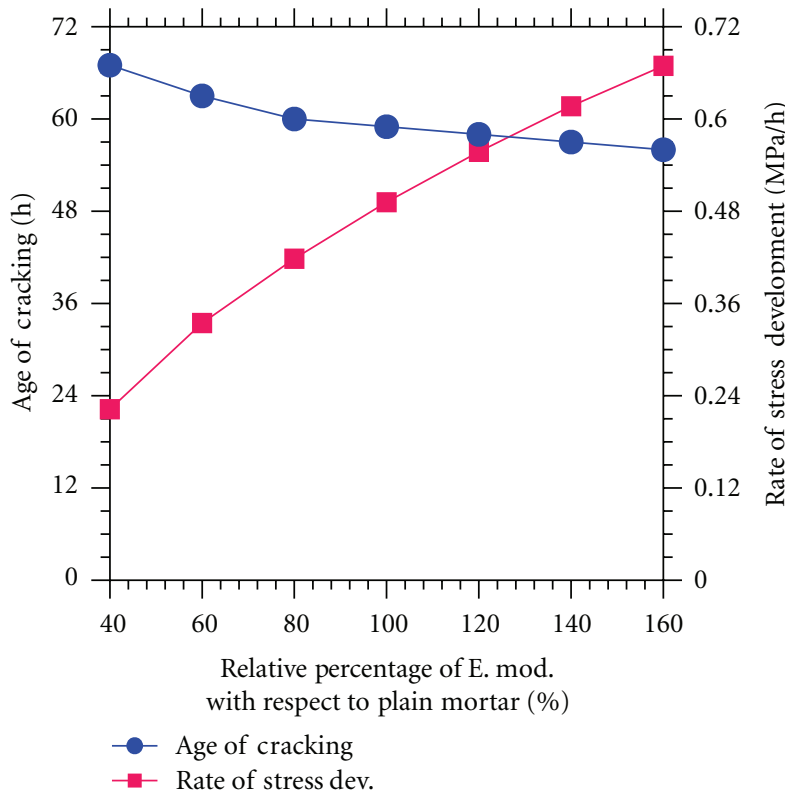

(a)

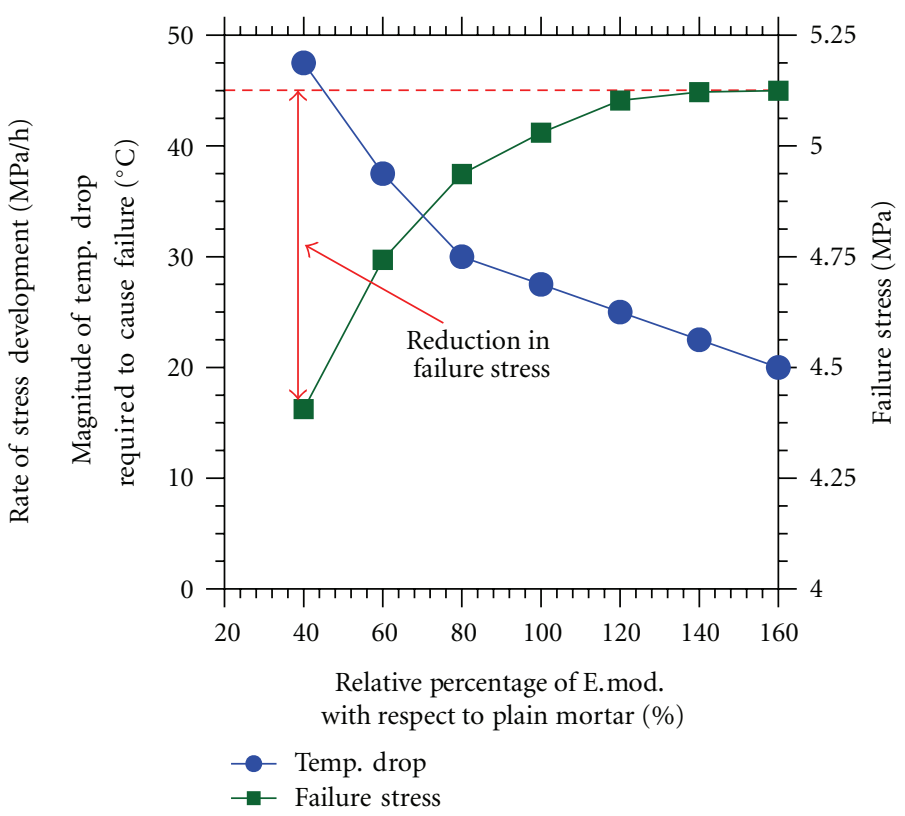

(b)

FIGURE 8: Influence of elastic modulus of the specimen on (a) the residual stress development, age of cracking, (b) the magnitude of temperature drop, and the reduction in strength.

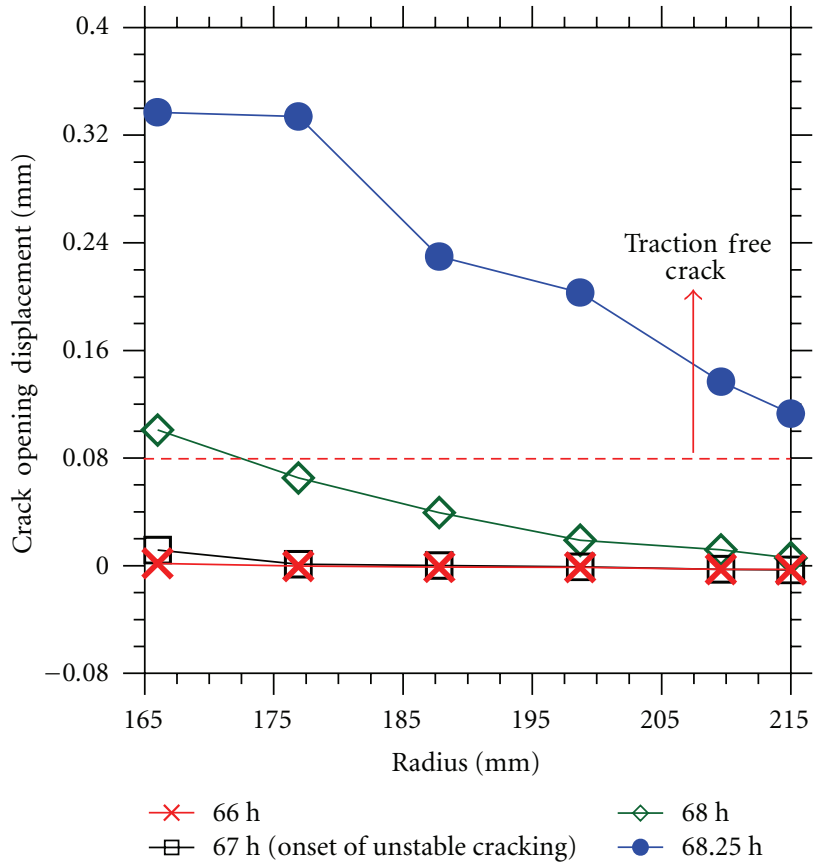

(a)

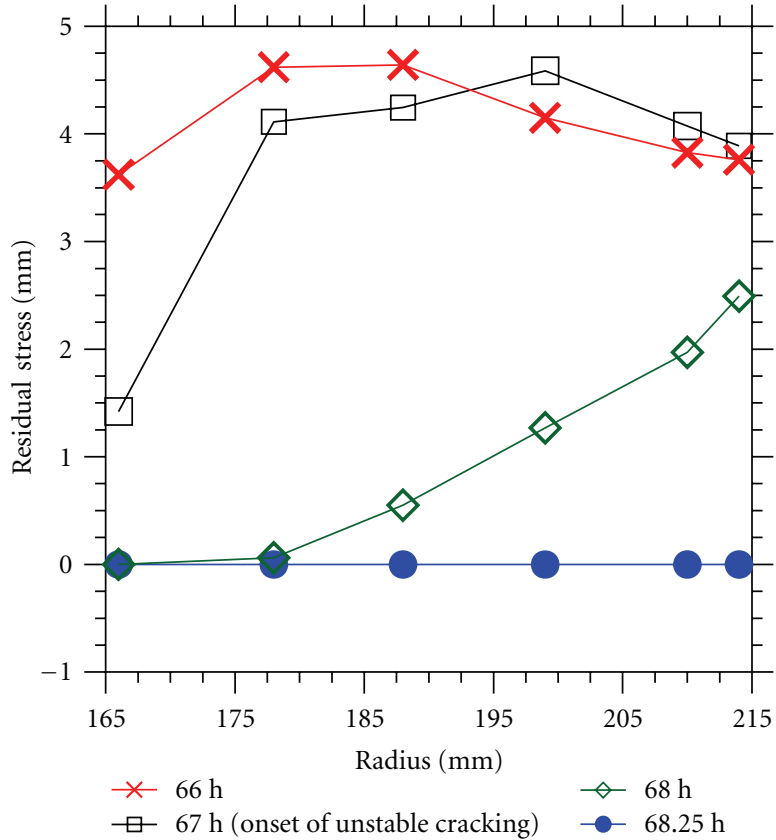

(b)

Figure 9: (a) Crack opening displacement and (b) residual stress development through the specimen wall in the damage zone when the elastic modulus was reduced by $60 \%$.

significant when the reduction in the mortar elastic modulus exceeded $20 \%$.

4.2. Influence of Coefficient of Thermal Expansion of Invar and Concrete. When the dual ring was cooled, both the concrete and the two restraining rings underwent different rates of thermal deformations as based on their respective COTEs. As such, the rate of thermal stress development was greatly dependent on the COTEs of the mortar material and restraining rings. Although a similar linear COTE of 


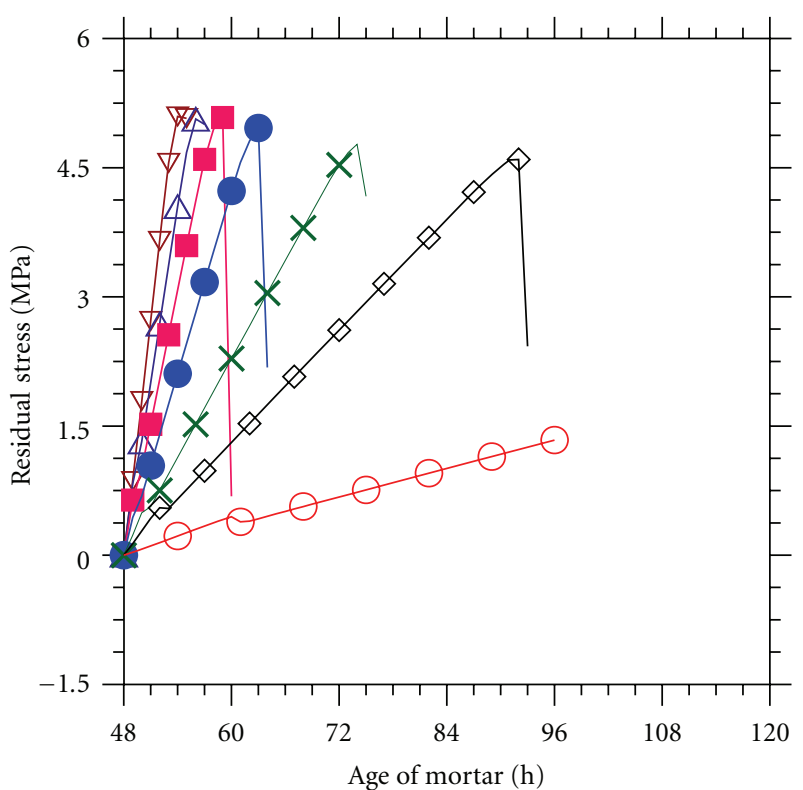

Concrete COTE

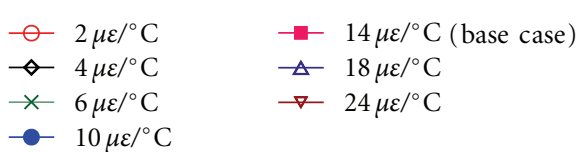

(a)

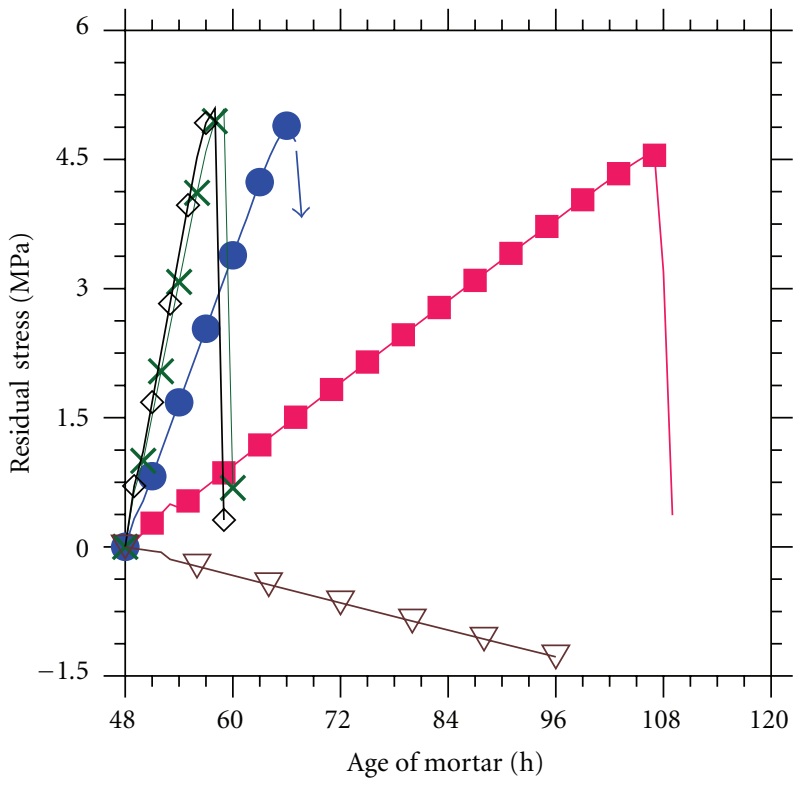

COTE of rest. rings

$$
\begin{array}{ll}
\smile 0 \mu \varepsilon /{ }^{\circ} \mathrm{C} & -12 \mu \varepsilon /{ }^{\circ} \mathrm{C}(\text { steel }) \\
\times 1.3 \mu \varepsilon /{ }^{\circ} \mathrm{C} \text { (invar) } & \nabla 18 \mu \varepsilon /{ }^{\circ} \mathrm{C} \\
\rightarrow-7 \mu \varepsilon /{ }^{\circ} \mathrm{C} &
\end{array}
$$

(b)

FIGURE 10: Influence of (a) COTE of the mortar specimen and (b) COTE of restraining rings on the average residual stress development.

$14 \mu \varepsilon /{ }^{\circ} \mathrm{C}$ was used for all mortar mixtures in this study, it must be mentioned that the COTE is highly dependent on the aggregate composition, aggregate volume, moisture content, and the presence of LWA particles [2, 45, 46]. It has been reported that a concrete with lightweight aggregates generally has a smaller COTE than that of a concrete with normal weight aggregates [36-38]. This however was not observed in the mortars examined in this investigation.

To determine the sensitivity of the dual ring test to the COTE of the mortar, a series of simulations was performed. The COTE of the mortar specimen was varied from $2 \mu \varepsilon /{ }^{\circ} \mathrm{C}$ to $24 \mu \varepsilon /{ }^{\circ} \mathrm{C}$ as shown in Table 1 . The effects of the COTE on the stress development and on the cracking behavior are shown in Figure 10(a). As expected, the rate of stress development (i.e., the slope of the residual stress versus time curve) increased with increasing the COTE of the specimen. While thermal stresses in the specimen with a COTE of $24 \mu \varepsilon /{ }^{\circ} \mathrm{C}$ increased at a rate of $0.91 \mathrm{MPa} / \mathrm{h}$, the rate of stress development was diminished to $0.04 \mathrm{MPa} / \mathrm{h}$ when the COTE was reduced to $2 \mu \varepsilon /{ }^{\circ} \mathrm{C}$. Cracking occurred at an earlier age when the COTE of the mortar increased. Cracking occurred after $11 \mathrm{~h}$ of cooling in the base case specimen, while no cracking occurred after $48 \mathrm{~h}$ of cooling when the COTE of the mortar was reduced to $2 \mu \varepsilon /{ }^{\circ} \mathrm{C}$. It is further noticed that the average section stress of the ring specimens at failure was reduced as the COTE of the mortar and the rate of stress development were reduced. This reduction in the average stress of the ring specimens at failure can be attributed to higher stress relaxation and the corresponding stress redistribution along the radial direction in these specimens [47-49].

Restraining rings can theoretically be made from any material. If the COTE of the restraining ring is higher than that of the concrete, the restraining rings shrink more than the specimen upon cooling and the outer restraining ring would apply a compressive force on the specimen. Five series of simulations were performed in addition to the base case (i.e., the Invar rings) to determine the influence of the COTE of the restraining rings on stress development in the dual ring test. Restraining rings with COTE values of $0 \mu \varepsilon /{ }^{\circ} \mathrm{C}, 1.3 \mu \varepsilon /{ }^{\circ} \mathrm{C}$ (Invar), $7 \mu \varepsilon /{ }^{\circ} \mathrm{C}, 12 \mu \varepsilon /{ }^{\circ} \mathrm{C}$ (COTE for a typical steel), and $18 \mu \varepsilon /{ }^{\circ} \mathrm{C}$ were simulated. Figure 10 (b) illustrates the effect of the COTE of the restraining ring on the stress development in the dual ring specimen. It can be seen that when the COTE of the restraining rings approached that of the concrete, the rate of stress development in the specimen was greatly reduced. It should be noted that no stress would develop in the specimen if both concrete and restraining rings have the same COTE. As shown by the $\mathrm{COTE}_{\text {rest }}-18$ curve in Figure 10(b), a compressive stress started to develop in the specimen under cooling once the COTE of restraining rings exceeded that of the concrete specimen.

Figure 11(a) shows the influence of the relative thermal deformations of the specimen and the restraining ring (as shown by the difference between their COTEs) on the stress development and age of cracking. It can be seen that the rate of stress development was proportional to the difference between the COTEs of the mortar specimen and 


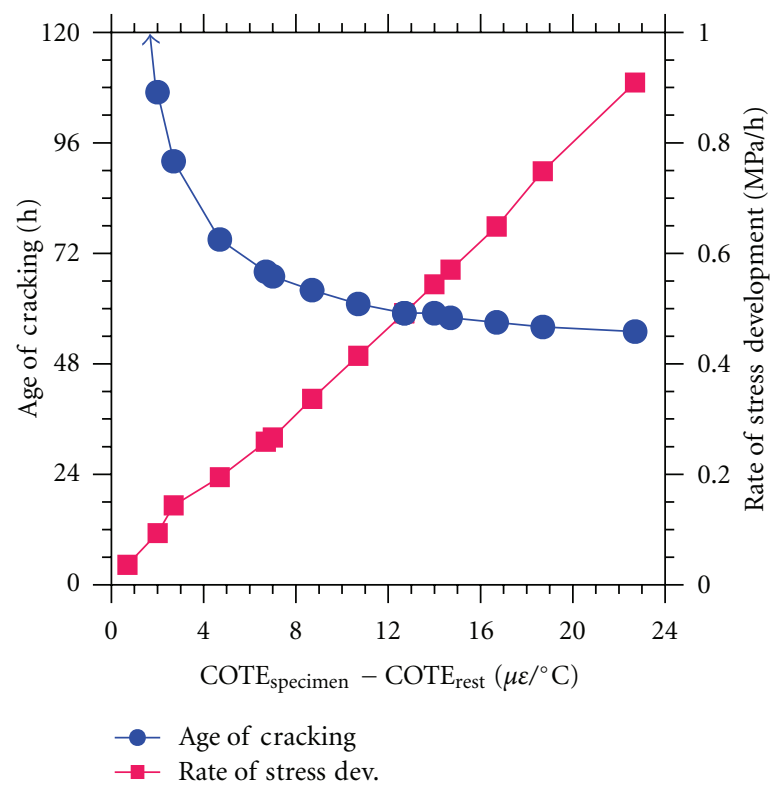

(a)

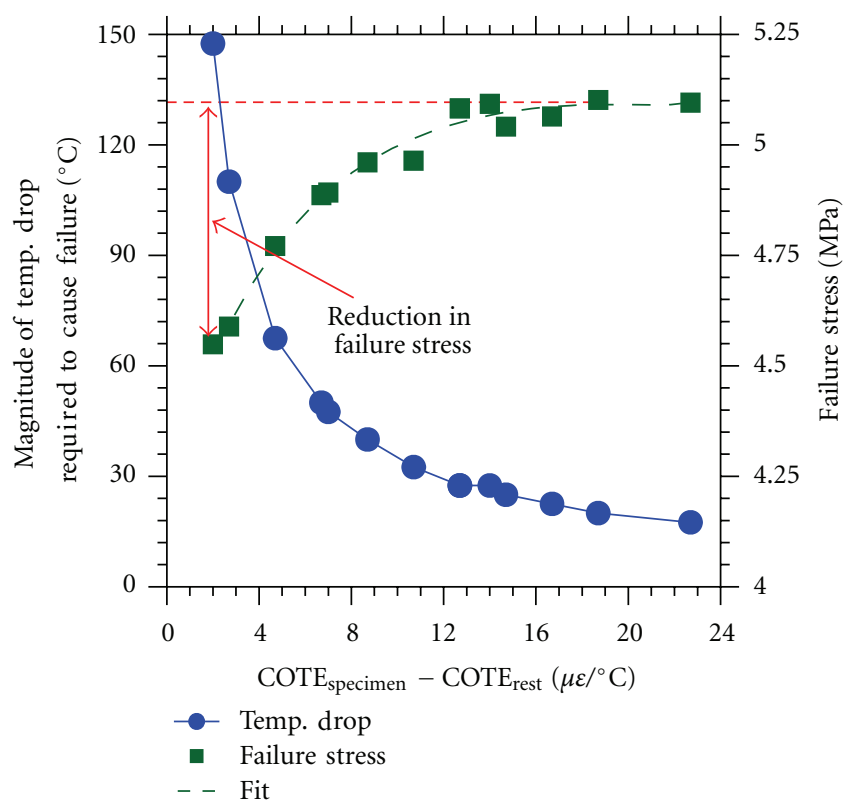

(b)

FIGURE 11: Influence of relative thermal deformations of the mortar and restraining rings on (a) the rate of stress development, age of cracking, (b) the magnitude of temperature drop, and the reduction in average stress of dual ring specimen at failure.

the restraining rings. As expected, as the difference between the COTEs of the specimen and the restraining rings was reduced, the rate of stress development was reduced and the specimen became less prone to cracking.

It can be seen that while a high stiffness material with a high COTE such as $12 \mu \varepsilon /{ }^{\circ} \mathrm{C}$ (COTE for a typical steel) may provide sufficient stiffness and can be conveniently used in the conventional restraining ring test (which is done at a constant temperature), it may not be so suitable to study the thermal cracking behavior of concrete in the dual ring test. Since the COTE for concrete typically varies between 5 and $15 \mu \varepsilon /{ }^{\circ} \mathrm{C}[36,37]$, using restraining rings with a high COTE may not be appropriate in dual ring test (Figure 11(b)). When restraining rings with such a high COTE are used, the restraint moves substantially with temperature variations, a higher extent of stress relaxation occurs, the average section stress of the specimen at failure is reduced, and a higher temperature drop is needed to crack the specimen. Consequently, the thermal cracking performance of concrete would be better assessed using restraining rings with a lower COTE, such as those made from Invar.

4.3. Influence of the Rate of Cooling. The influence of the rate of loading on the failure stress of concrete has been studied by various researchers in the past $[47,48,50-52]$. When the loading rate is reduced, stresses in concrete are relaxed due to effects of creep of concrete under sustained load, stresses are redistributed, and the average stress of specimens at failure is generally reduced $[47,50,51]$. A series of simulations was performed to quantify the influence of the rate of cooling on stress development in the dual ring test. Five cooling rates of $(0.5,1.0,2.0,3.0,5.0,8.0 \text {, and } 10.0)^{\circ} \mathrm{C} / \mathrm{h}$ were simulated in this series, in addition to the base case cooling rate of $2.5^{\circ} \mathrm{C} / \mathrm{h}$, as indicated in Table 1. No shrinkage was considered in the simulations and the cooling started at $48 \mathrm{~h}$.

Figure 12(a) illustrates the influence of the rate of cooling on the stress development and cracking in the dual ring test. As expected, the rate of stress development in the specimen increased with an increase in the rate of cooling. When the temperature was reduced at a faster rate, the thermal stresses developed faster and cracking occurred at an earlier age. While a minimal temperature gradient of $0.3^{\circ} \mathrm{C}$ was observed in the base case specimen, the temperature difference between the center and outer surfaces of the specimens exceeded $1^{\circ} \mathrm{C}$ when the cooling rate exceeded $8.0^{\circ} \mathrm{C} / \mathrm{h}$. As such, it is recommended to keep the cooling rate below $8.0^{\circ} \mathrm{C} / \mathrm{h}$ to limit the thermal stress gradient through the concrete cross-section. It should be noted that this rate of cooling is well above the cooling capacity of most conventional cooling devices and the highest rate of cooling will likely be limited by the cooling device.

Figure 12(b) shows that the magnitude of the temperature drop necessary to induce cracking was highly dependent on the rate of cooling. As the cooling rate was reduced, a higher magnitude of temperature drop was needed to crack the specimen. The magnitude of the required temperature drop increased significantly once the cooling rate became smaller than $2.5^{\circ} \mathrm{C} / \mathrm{h}$. For example, while only a temperature drop of $27.5^{\circ} \mathrm{C}$ was needed to crack the specimen at the cooling rate of $2.5^{\circ} \mathrm{C} / \mathrm{h}$, the computed magnitude of the temperature drop was increased to $122.5^{\circ} \mathrm{C}$ at the cooling rate of $0.5^{\circ} \mathrm{C} / \mathrm{h}$. As such, a specimen may or may not crack in the dual ring test depending on the cooling rate. The influence of the cooling rate on average stress of the specimen at failure is shown in Figure 12(b). The failure load of the specimen began to decrease once the loading rate 


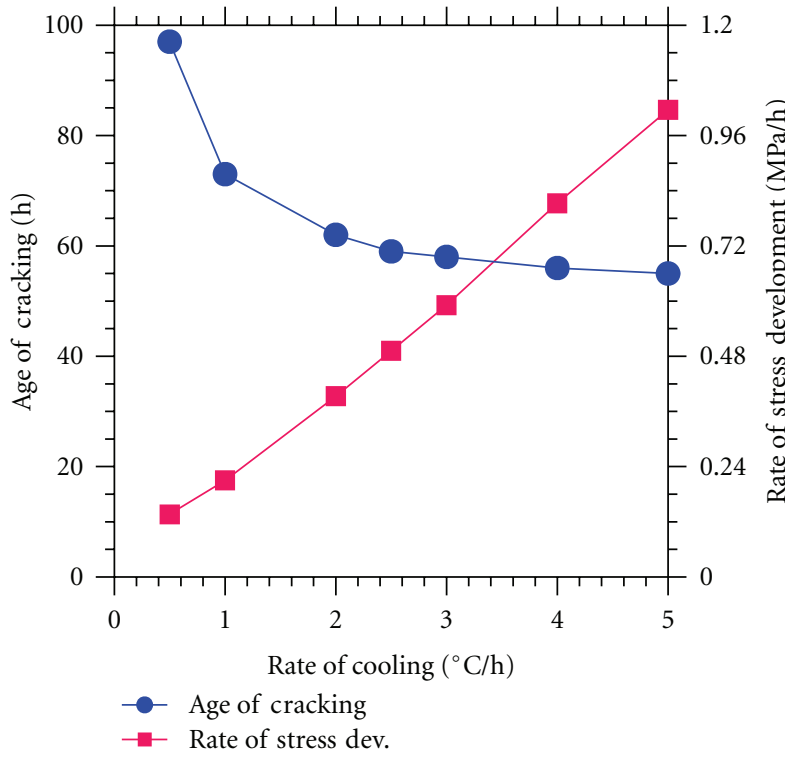

(a)

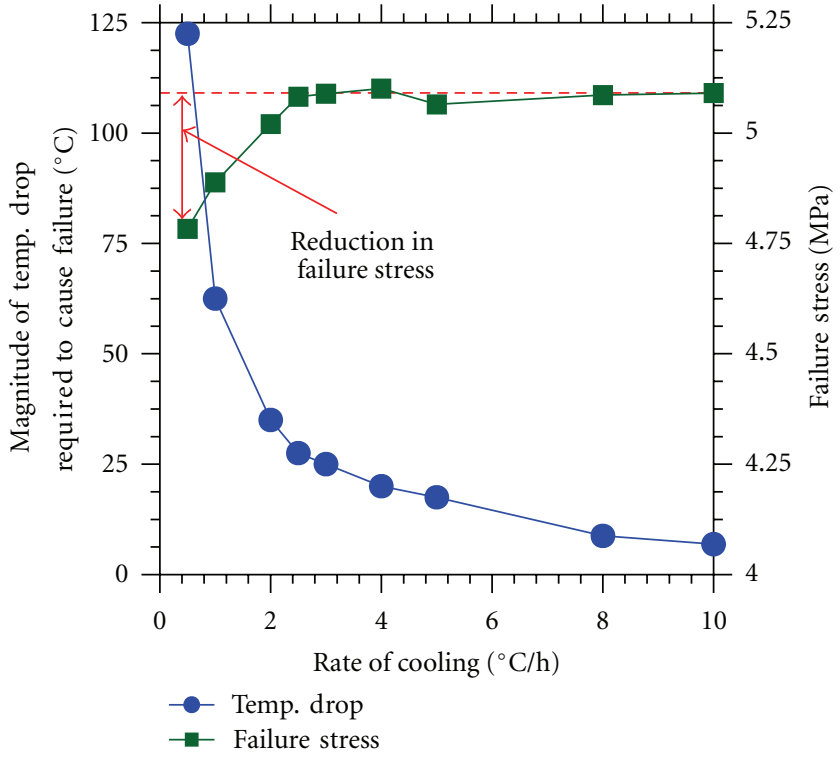

(b)

FIGURE 12: Influence of the rate of cooling on (a) the stress development and the age of cracking, and (b) the magnitude of temperature reduction and the average stress at failure in the dual ring test.

became smaller than $2.5^{\circ} \mathrm{C} / \mathrm{h}$ and specimens began to crack at noticeably later ages. The stress relaxation of concrete increased as specimens cracked at later ages. The higher stress relaxation resulted in the formation of more compliant cracks and the corresponding stress redistribution. The stress redistribution reduced the average stress through the crosssection at failure as the rate of thermal loading decreased.

4.4. Influence of Creep and Stress Relaxation. Due to the lower stiffness of the LWA, the creep and stress relaxation of mortar materials containing LWA is generally expected to increase with increasing the volume of low-stiffness LWA $[22,42]$. However, the increase in cement hydration due to the internal curing results in a reduction in the creep and stress relaxation of mortar materials [53]. As such, the net effect of prewetted LWA on the creep and stress relaxation of mortar materials depends on both the volume of lowstiffness LWA and the beneficial contribution of the internal curing on cement hydration. A series of simulations was performed to assess the influence of stress relaxation on the stress development and cracking potential in the dual ring test. The coefficients of the Maxwell chain model for the plain mortar were modified to increase the stress relaxation. The percent increase in stress relaxation relative to the plain mortar was then calculated by comparing the calculated relaxed stresses with the stress development of the plain mortar specimen. Five different cases with increasing stress relaxations of $5 \%, 13 \%, 22 \%, 32 \%$, and $42 \%$ were simulated as designated by $R-5, R-13, R-22, R-32$, and $R-42$ in Table 1 , respectively. It should be noted that the only difference in each case was the level of stress relaxation.

Figure 13(a) shows the influence of the stress relaxation on the rate of stress development in the dual ring specimens.
As expected, when the stress relaxation increased, stresses developed at a lower rate, the magnitude of the temperature drop to induce cracking was increased (Figure 13(b)), and cracking occurred at a later age, resulting in a lower cracking potential at higher levels of stress relaxation. Figure 13(b) shows that the average failure stress of the specimens decreased nearly linearly with increasing stress relaxation. This can be attributed to an increase in the compliance of cracks due to an increase in stress relaxation, resulting in a stress redistribution and a concurrent reduction in the average stresses in the ring at the time of unstable cracking.

4.5. Influence of Shrinkage of Concrete. Thermal and shrinkage effects are known as two main causes of early-age cracking in concrete elements. When both thermal and shrinkage effects are present, both factors contribute to the stress development and cracking. The contribution of each factor to cracking can vary based on environmental conditions and mixture properties.

A series of simulations was performed to illustrate the influence of autogenous shrinkage on the thermal cracking behavior in the dual ring test. Seven different cases were simulated. The primary difference among the simulations was the magnitude of the autogenous shrinkage. The input shrinkage values for each case were modified by $-140 \%$, $-120 \%,-60 \%,-40 \%,-20 \%,+20 \%,+40 \%$, and $+60 \%$ as designated by $\mathrm{Sh}+102, \mathrm{Sh}+51, \mathrm{Sh}-102, \mathrm{Sh}-153$, Sh - 204, Sh - 306, Sh - 357, and Sh - 408, respectively. The number following the "Sh" letters in these designations indicates the value of autogenous shrinkage at $48 \mathrm{~h}$. All other model inputs were held the same as those of the plain mortar as indicated in Table 1 . The cooling began after $48 \mathrm{~h}$ from the time of casting in all cases. As such, the specimens were 


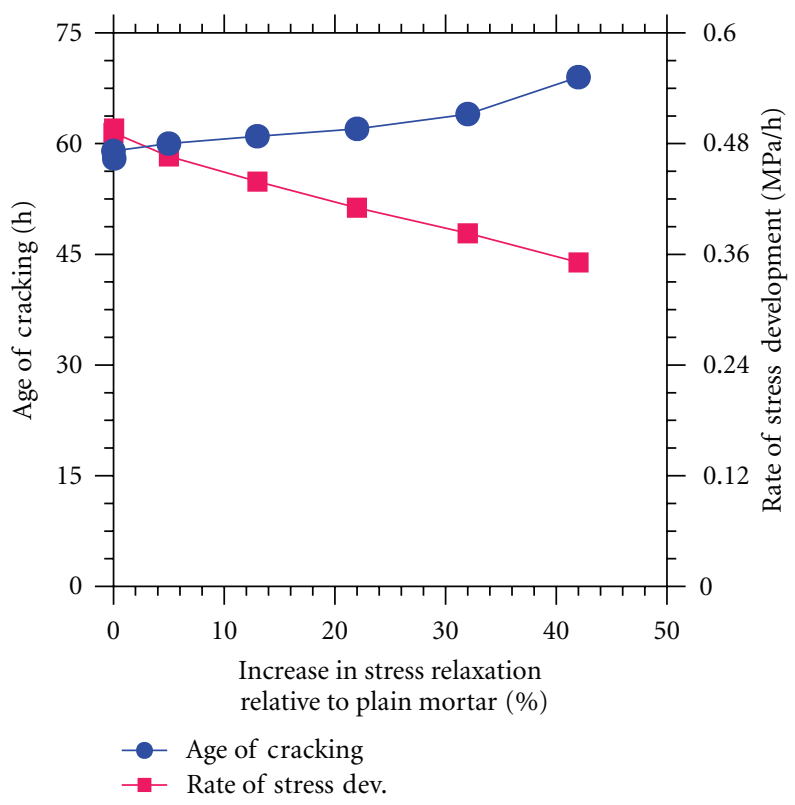

(a)

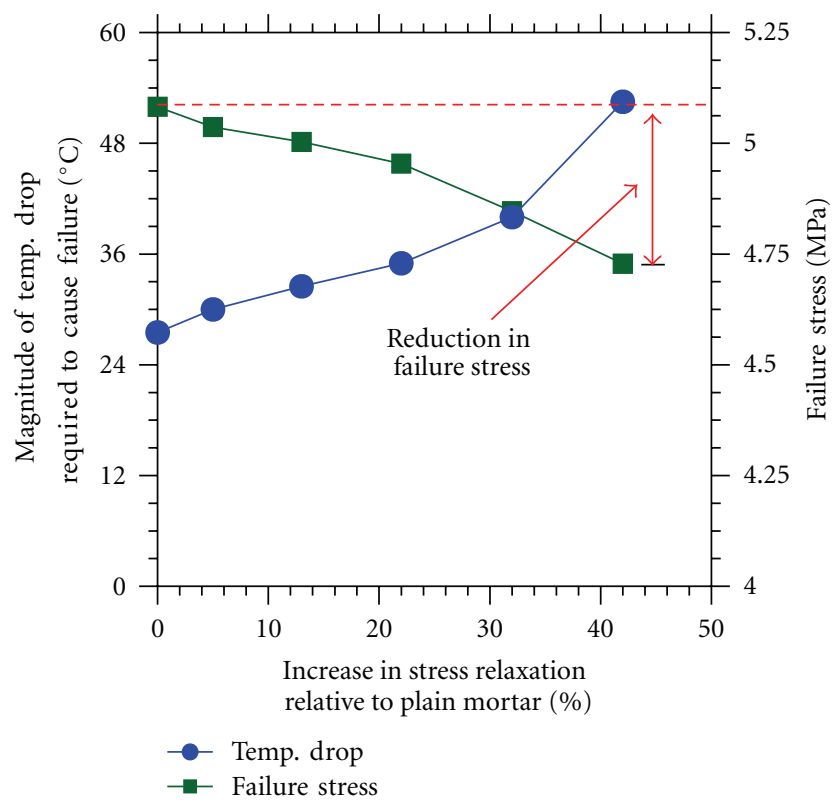

(b)

Figure 13: Influence of stress relaxation on (a) the stress development and the age of cracking, and (b) the magnitude of temperature reduction and the average stress at failure in the dual ring test.

only subjected to autogenous shrinkage deformations during the first $48 \mathrm{~h}$ while they were subjected to simultaneous shrinkage and temperature deformations after $48 \mathrm{~h}$. It should be noted that the $S h+102$ and $S h+51$ specimens simulate thermal stress development in specimens that were subjected to an initial autogenous expansion.

Figure 14(a) illustrates the influence of shrinkage on the stress development and cracking in the dual ring test. The stress development in all specimens, as expected, was proportional to the autogenous shrinkage values during the first $48 \mathrm{~h}$. For example, the stress level in $\mathrm{Sh}+102$ specimen with a shrinkage level of $+102 \mu \varepsilon$ at $48 \mathrm{~h}$ was $-0.22 \mathrm{MPa}$ (the negative sign indicates compressive stress) while the stress level in the Sh - 306 specimen with a $48 \mathrm{~h}$ shrinkage level of $-306 \mu \varepsilon$ was $3.96 \mathrm{MPa}$. It should be noted that due to their high shrinkage intensities, the Sh -357 and Sh -408 specimens cracked $38 \mathrm{~h}$ and $21 \mathrm{~h}$ after the time of casting, respectively. As such, they were not subjected to thermal loading and their rate of thermal stress development and temperature drop are noted by N.A. in Table 1 .

Once the cooling started, stresses began to increase at the rate of $0.518 \mathrm{MPa} / \mathrm{h}$ in all specimens (Figure $14(\mathrm{a})$ ). However, the rate of stress development began to decrease once the shrinkage magnitude exceeded $204 \mu \varepsilon$ at $48 \mathrm{~h}$. For example, the rate of stress development is reduced to $0.456 \mathrm{MPa} / \mathrm{h}$ in the case of Sh -306 specimen. This can be explained by the formation of shrinkage-induced cracks before the cooling began at $48 \mathrm{~h}$. When shrinkage-induced stresses reached the tensile strength at the inner surface of the Sh - 306 specimen at $36 \mathrm{~h}$, cracking began and propagated in a stable fashion in the specimen. The growth of the crack between $36 \mathrm{~h}$ and $48 \mathrm{~h}$ (when the cooling began) reduced the stiffness of the specimen, resulting in a slower rate of stress development once the cooling started. It should be noted that the specimens with higher shrinkage intensities (i.e., the Sh - 357 and Sh -408 specimens) cracked before cooling began and are not discussed further.

The influence of autogenous shrinkage on the average stresses at the failure of the dual ring specimens is illustrated in Figure 14(b). Due to the high rate of cooling (i.e., $2.5^{\circ} \mathrm{C} / \mathrm{h}$ ), no significant stress redistribution occurred and the average section stress of the specimens remained insensitive to the autogenous shrinkage. Figure 14(b) shows that the magnitude of temperature drop decreased linearly with an increase in the autogenous shrinkage of the specimens. The specimens were more prone to thermal cracking when they were exposed to high levels of shrinkage-induced stresses before the start of cooling. In contrast and as expected, the specimens that experienced early-age autogenous expansion illustrated a better thermal cracking performance and cracked last (Figure 14(a)).

4.6. Influence of Thermal Heat Capacity. It has been reported that the specific heat capacity of concrete is a function of the water content and density of concrete [6]. As a result, the heat capacity of concrete made with prewetted LWA is expected to increase with the amount of internal curing water and reduce with increasing the volume of low-density LWA. To determine the influence of variations in the volumetric heat capacity on the rate of thermal stress development in the dual ring test, another series of simulations was performed. As shown in Table 1, four cases were modeled in addition to the base case specimen, where the primary difference between each case was the value of heat capacity. The magnitude of the volumetric heat capacity of the plain mortar (i.e., base case 


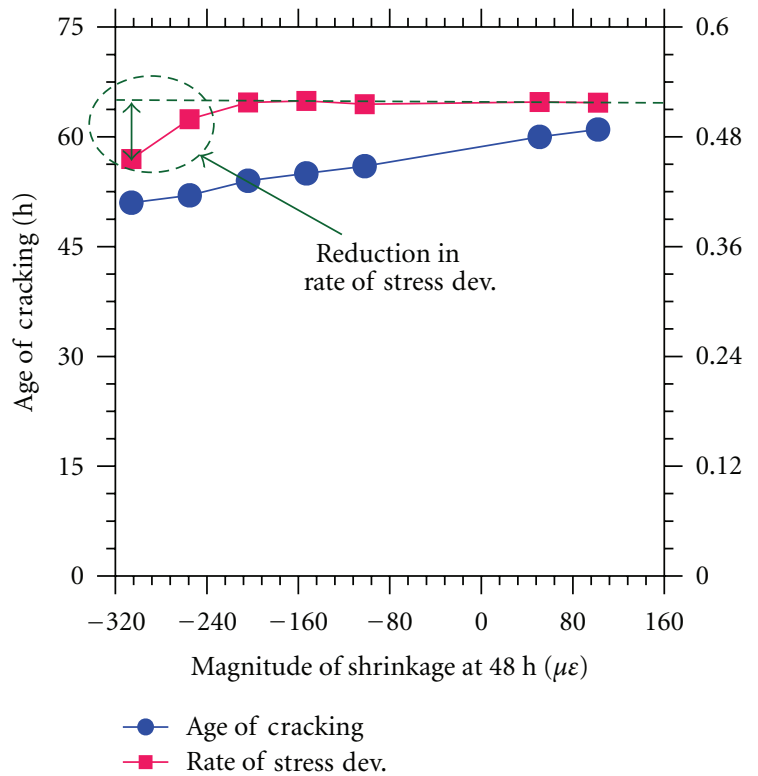

(a)

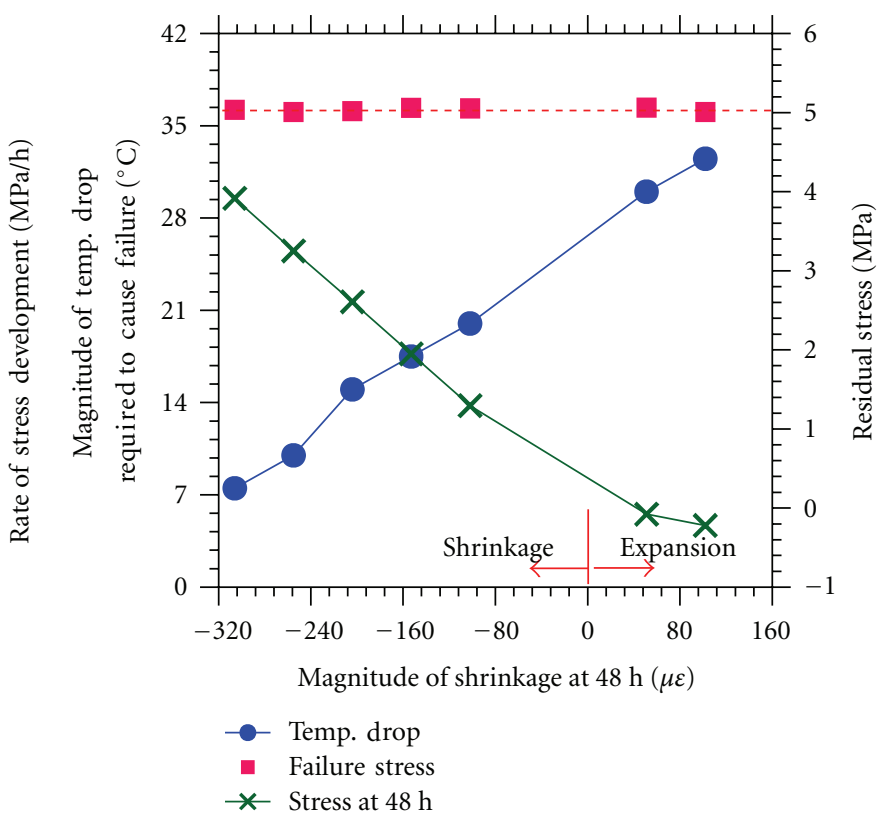

(b)

FIGURE 14: Influence of autogenous shrinkage on (a) the stress development and the age of cracking, (b) the magnitude of temperature reduction, stresses at $48 \mathrm{~h}$, and the average section stress at failure in dual ring test.

specimen), $2100 \mathrm{~kJ} /\left(\mathrm{m}^{3} \cdot \mathrm{K}\right)$, was varied by $\pm 10 \%$ and $\pm 20 \%$ in each simulation. The results indicated that the thermal stress development and cracking behavior of the specimen in the dual ring test were not sensitive to the changes in heat capacity. This can be explained by the fact that the dual ring test is a temperature controlled test. Since it was the temperature of the system that was controlled (not the amount of heat flow from the system), the heat capacity of the specimen was not a significant material property in the dual ring testing.

\section{Conclusions}

The dual ring geometry was modeled using finite element analysis. A parametric study was performed to examine the thermal cracking behavior of concrete mixtures containing prewetted lightweight aggregates by quantifying the individual contribution of several material properties. Knowing the dual ring test's sensitivity to these material properties would help to better interpret the results of dual ring testing. The following conclusions can be made based on the simulation results.

Stresses developed at a slower rate and cracking occurred at a later age when the elastic modulus of concrete was reduced (i.e., the concrete was more compliant). As such, a larger temperature drop was needed to crack the specimen with a lower elastic modulus. Due to the higher compliance, significant unloading and stress redistribution was observed during crack propagation in the dual ring specimen with a reduced elastic modulus. This resulted in a lower average concrete section stress at the time of failure. This behavior became more significant when the elastic modulus of concrete was reduced by more than $20 \%$ and greater stress relaxation occurred.

Stress development and cracking behavior were influenced by the COTE of the specimen and the COTE of the restraining rings. It was determined that the rate of stress development in the dual ring test was directly proportional to the difference between the COTEs of the specimen and that of the restraining rings. When the COTE of the restraining rings was increased, stresses developed at a slower rate. As a result, the thermal cracking resistance of concrete can be viewed as being artificially improved by using a restraining ring with a COTE value near that of concrete. Consequently, it is recommended that Invar or other materials with minimal COTE should be used.

As expected, the rate of stress development was proportional to the rate of cooling in the dual ring test. As the rate of cooling of the specimen was reduced, a higher temperature drop was needed to crack the specimen. It was shown that cracking may or may not occur in a dual ring specimen, depending on the rate of cooling. The slowest rate of cooling recommended is $2.5^{\circ} \mathrm{C} / \mathrm{h}$. When the cooling rate exceeded $8^{\circ} \mathrm{C} / \mathrm{h}$, a considerable temperature difference between the center and boundary of the specimen developed. To limit the thermal stress gradient through the concrete cross section, it is recommended to keep the cooling rate below $8.0^{\circ} \mathrm{C} / \mathrm{h}$.

When the stress relaxation and creep of the specimen were increased, the rate of stress development was reduced and a higher temperature drop was needed to crack the specimen. Higher stress relaxation resulted in a more compliant crack and corresponding stress redistribution and unloading in the cracked region. 
The thermal cracking performance of the specimens improved with reducing their autogenous shrinkage. While the magnitude of shrinkage did not affect the rate of stress development, the temperature drop necessary to induce cracking was increased when decreasing the autogenous shrinkage. At high shrinkage levels, the presence of shrinkage induced cracks reduced the stiffness of the specimen, thereby reducing the rate of thermal stress development when the cooling was initiated.

\section{Acknowledgments}

This work was conducted in the Pankow Materials Laboratory and the Materials Sensing and Characterization Laboratory at the Purdue University. The authors would like to acknowledge the support which has made these laboratories and this research possible. This work is supported by the FHWA, JTRP, and ESCSI, which are gratefully acknowledged.

\section{References}

[1] ACI-207.2R-95, "Effect of restraint, volume change, and reinforcement on cracking of mass concrete," ACI2072R-95, American Concrete Institute, 1995.

[2] R. Springenschmid, Prevention of Thermal Cracking in Concrete at Early Ages (Rilem Report), Spon Press, 1998.

[3] J. H. Moon, F. Rajabipour, B. Pease, and J. Weiss, "Quantifying the influence of specimen geometry on the results of the restrained ring test," Journal of ASTM International, vol. 3, no. 8, pp. 1-14, 2006.

[4] W. J. Weiss, Prediction of Early-Age Shrinkage Cracking in Concrete, Northwestern University, Evanston, III, USA, 1999.

[5] K. Raoufi, E. S. Bernard, and W. J. Weiss, "Shrinkage cracking behavior of fiber reinforced concrete: as assessed using the restrained ring test," Journal of ASTM International, vol. 7, no. 7, p. 15, 2010.

[6] D. P. Bentz, "A review of early-age properties of cement-based materials," Cement and Concrete Research, vol. 38, no. 2, pp. 196-204, 2008.

[7] K. Raoufi, Saw-cutting guidelines for concrete pavements: examining the requirements for time and depth of saw-cutting, M.S. thesis, Purdue University, West Lafayette, Ind, USA, 2007.

[8] K. Raoufi, J. Weiss, and T. Nantung, "Numerical assessment of saw-cutting: the influence on stress development and cracking," in Pavement Cracking: Mechanisms, Modeling, Detection, Testing and Case Histories, I. L. Al-Qadi, T. Scarpas, and A. Loizos, Eds., pp. 109-118, CRC Press, 2008.

[9] J. L. Schlitter, A. H. Senter, D. P. Bentz, T. Nantung, and W. J. Wei, "A dual concentric ring test for evaluating residual stress development due to restrained volume change," Journal of ASTM International, vol. 7, no. 9, p. 13, 2010.

[10] D. P. Bentz, G. Sant, and J. Weiss, "Early-age properties of cement-based materials. I: Influence of cement fineness," Journal of Materials in Civil Engineering, vol. 20, no. 7, pp. 502508, 2008.

[11] J. Weiss, P. Lura, F. Rajabipour, and G. Sant, "Performance of shrinkage-reducing admixtures at different humidities and at early ages," ACI Materials Journal, vol. 105, no. 5, pp. 478-486, 2008.

[12] C. E. Guillaume, "Invar and its applications," Nature, vol. 71, no. 1832 , pp. 134-139, 1905.
[13] B. S. Lement, B. L. Averbach, and M. Cohen, "The dimensional behavior of invar," Transactions of the American Society for Metals, vol. 41, pp. 1072-1097, 1951.

[14] Y. Nakamura, "Invar problem," IEEE Transactions on Magnetics, vol. 12, no. 4, pp. 278-291, 1976.

[15] A. Radlinska, B. Bucher, and J. Weiss, "Comments on the interpretation of results from the restrained ring test," Journal of ASTM International, vol. 5, no. 10, p. 12, 2008.

[16] B. Pease, The role of shrinkage reducing admixtures on shrinkage, stress development, and cracking, M.S. thesis, Purdue University, West Lafayette, Ind, USA, 2005.

[17] A. Radlinska, J. Moon, F. Rajabipour, and J. Weiss, "The ring test: a review of recent developments," in Proceedings of the International RILEM Conference on Volume Changes of Hardening Concrete: Testing and Mitigation, O. M. Jensen, P. Lura, and K. Kovler, Eds., p. 9, 2006.

[18] S. Kim, S. Sargand, and A. Wargo, "A simple test procedure for evaluating low temperature crack resistance of asphalt concrete," Tech. Rep., Ohio Department of Transportation, Columbus, Ohio, USA, 2009.

[19] J. Schlitter, T. Barrett, and W. Weiss, "Restrained shrinkage behavior due to combined autogenous and thermal effects in mortars containing super absorbent polymer (SAP)," in Proceedings of the International RILEM Conference on Use of Superabsorbent Polymers and Other New Additives in Concrete, Technical University of Denmark, Lyngby, Denmark, 2010.

[20] D. P. Bentz and O. M. Jensen, "Mitigation strategies for autogenous shrinkage cracking," Cement \& Concrete Composites, vol. 26, no. 6, pp. 677-685, 2004.

[21] RILEM-TC-196, "Internal curing of concrete, state-of-the-art report of RILEM technical committee 196-ICC," Tech. Rep., Bagneux RILEM Publications S.A.R.L, France, 2007.

[22] K. Shin, B. Bucher, and J. Weiss, "Role of lightweight synthetic particles on the restrained shrinkage cracking behavior of mortar," Journal of Materials in Civil Engineering, vol. 23, no. 5, 9 pages, 2011.

[23] J. Schlitter, New methods to quantify the cracking performance of cementitious systems made with internal curing, M.S. thesis, Purdue University, West Lafayette, Ind, USA, 2010.

[24] K. Raoufi, Restrained Shrinkage Cracking Of Concrete: The Influence of Damage Localization, Purdue University, West Lafayette, Ind, USA, 2010.

[25] FEMMASSE-MLS8.5-User-Manual. Finite Element Modules for Material Science and Structural Engineering. Netherland: MLS Version 8.5, FEMMASSE B.V., 2006.

[26] ASTM-C1581-09a, "ASTM-C1581-09a: standard test method for determining age at cracking and induced tensile stress characteristics of mortar and concrete under restrained shrinkage," Annual Book of ASTM Standards, ASTM International, West Conshohocken, Pa, USA, 2009.

[27] J. Schlitter, D. Bentz, and W. J. Weiss, "Quantifying reserve cracking capacity using a dual ring device and a temperature drop," ACI Materials Journal. In press.

[28] Z. Bazant and J. Planas, Fracture and Size Effect in Concrete and Other Quasibrittle Materials, CRC Press, Boca Raton, Fla, USA, 1st edition, 1998.

[29] A. B. Hossain and J. Weiss, "Assessing residual stress development and stress relaxation in restrained concrete ring specimens," Cement \& Concrete Composites, vol. 26, no. 5, pp. 531-540, 2004.

[30] ASTM-C496-04, "Standard test methods for splitting tensile strength of cylindrical concrete specimens," Annual Book of ASTM Standards, ASTM International, West Conshohocken, Pa, USA, 2009. 
[31] ASTM-C469-02, "Standard test method for static modulus of elasticity and poisson's ratio of concrete in compression," Annual Book of ASTM Standards, ASTM International, West Conshohocken, Pa, USA, 2009.

[32] ASTM-C1698-09, "Standard test method for autogenous strain of cement paste and mortar," Annual Book of ASTM Standards, ASTM International, West Conshohocken, Pa, USA, 2009.

[33] ASTM-C403-08, "Standard test method for time of setting of concrete mixtures by penetration resistance," Annual Book of ASTM Standards, ASTM International, West Conshohocken, Pa, USA, 2009.

[34] SYSTAT, TableCurve 2D, Automated Curve Fitting \& Equation Discovery, 5.01 version, SYSTAT Software, 2002.

[35] ASTM-C490/C490M-09, Standard Practice for Use of Apparatus for the Determination of Length Change of Hardened Cement Paste, Mortar, and Concrete, ASTM International, West Conshohocken, Pa, USA, 2009.

[36] ACI-Committee-213, "CI 213R-03: guide for structural lightweight-aggregate concrete," Tech. Rep. ACI-213R-03, American Concrete Institute, 2003.

[37] I. Martin, "Environment effect on thermal variations and shrinkage of lightweight concrete structures," ACI Journal Proceedings, vol. 69, no. 3, pp. 179-184, 1972.

[38] K. A. Riding, J. L. Poole, A. K. Schindler, M. C. G. Juenger, and K. J. Folliard, "Effects of construction time and coarse aggregate on bridge deck cracking," ACI Materials Journal, vol. 106, no. 5, pp. 448-454, 2009.

[39] K. Van Breugel, "Prediction of temperature development in hardening concrete," in Prevention of Thermal Cracking in Concrete at Early Ages, R. Springenschmid, Ed., pp. 51-75, E \& FN Spon, London, UK, 1998.

[40] L. Østergaard, Early-age fracture mechanics and cracking of concrete experiments and modeling, Ph.D. thesis, Technical University of Denmark, 2003.

[41] W. Findley, J. Lai, and K. Onaran, Creep and Relaxation of Nonlinear Viscoelastic Materials: with an Introduction to Linear Viscoelasticity, Dover Publications, New York, NY, USA, 1989.

[42] D. Hobbs, "The dependence of the bulk modulus, Young's modulus, creep, shrinkage and thermal expansion of concrete upon aggregate volume concentration," Materials and Structures, vol. 4, no. 2, pp. 107-114, 1971.

[43] R. Henkensiefken, Internal curing in cementitious systems made using saturated lightweight aggregate, M.S. thesis, Purdue University, West Lafayette, Ind, USA, 2008.

[44] J. H. Moon and J. Weiss, "Estimating residual stress in the restrained ring test under circumferential drying," Cement and Concrete Composites, vol. 28, no. 5, pp. 486-496, 2006.

[45] A. Neville, Properties of Concrete, Wiley, 4th edition, 1996.

[46] A. A. Khan, W. D. Cook, and D. Mitchell, "Thermal properties and transient thermal analysis of structural members during hydration," ACI Materials Journal, vol. 95, no. 3, pp. 293-303, 1998.

[47] E. Attiogbe, J. Weiss, and H. See, "A look at the rate of stress versus time of cracking relationship observed in the restrained ring test," in Proceedings of the international RILEM Symposium on Advances in Concrete through Science and Engineering, Evanston, Ill, USA, 2004.

[48] S. Shah, S. Swartz, and C. Ouyang, Fracture Mechanics of Concrete: Applications of Fracture Mechanics to Concrete, Rock and Other Quasi-Brittle Materials, John Wiley \& Sons, 1995.

[49] Y. H. Jenq and S. P. Shah, "Two-parameter fracture model for concrete," ASCE Journal of Engineering Mechanics, vol. 111, no. 10, pp. 1227-1241, 1985.
[50] Z. P. Bazant and R. Gettu, "Rate effects and load relaxation in static fracture of concrete," ACI Materials Journal, vol. 89, no. 5, pp. 457-468, 1992.

[51] M. Emborg, "Development of mechanical behaviour at early ages," in Prevention of Thermal Cracking in Concrete at Early Ages (Rilem Report), R. Springenschmid, Ed., pp. 76-148, Spon Press, London, UK, 1998.

[52] F. H. Wittmann, P. E. Roelfstra, H. Mihashi, Y. Y. Huang, X. H. Zhang, and N. Nomura, "Influence of age of loading, water-cement ratio and rate of loading on fracture energy of concrete," Materials and Structures, vol. 20, no. 2, pp. 103-110, 1987.

[53] M. Lopez, L. F. Kahn, and K. E. Kurtis, "Effect of internally stored water on creep of high-performance concrete," ACI Materials Journal, vol. 105, no. 3, pp. 265-273, 2008. 

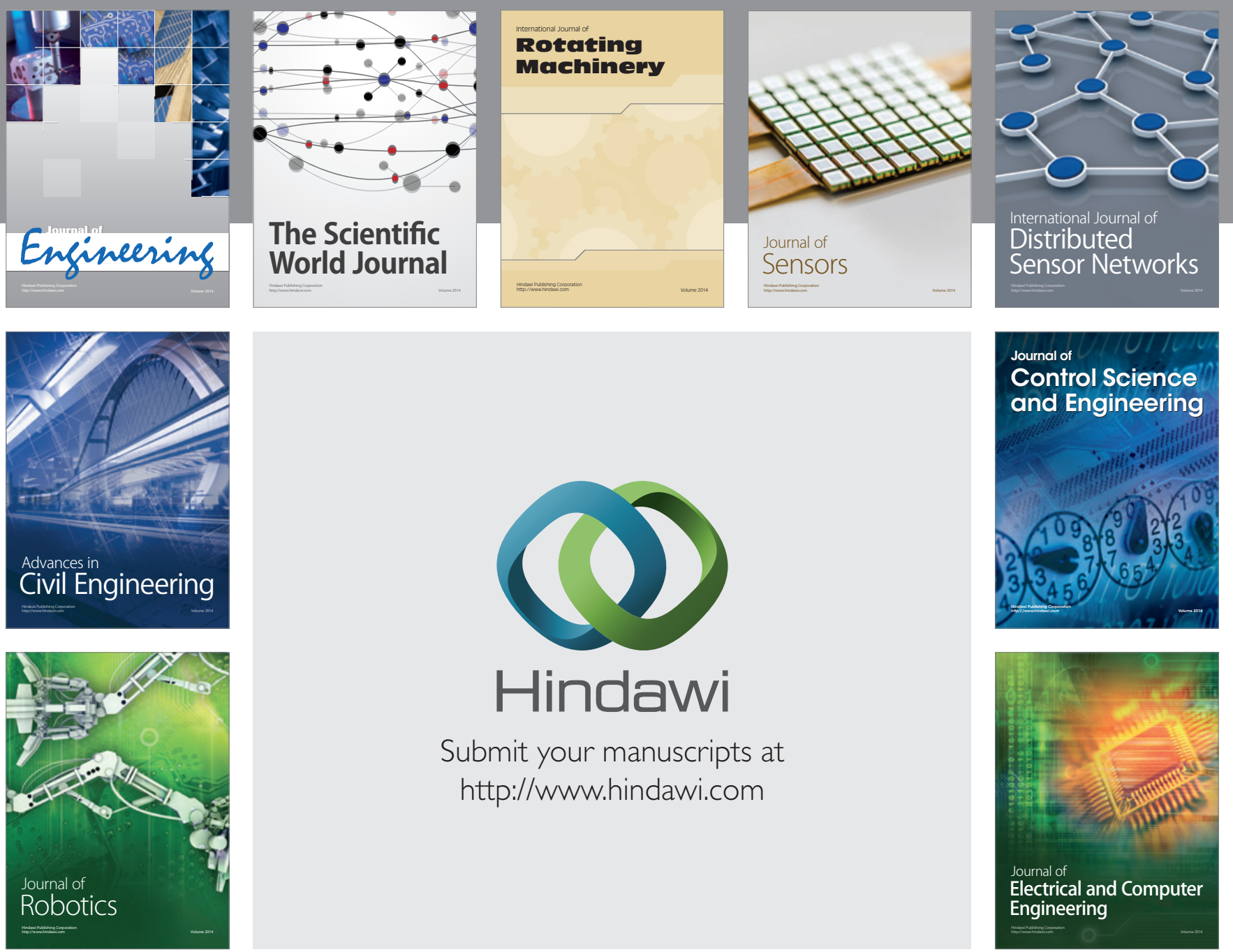

Submit your manuscripts at

http://www.hindawi.com
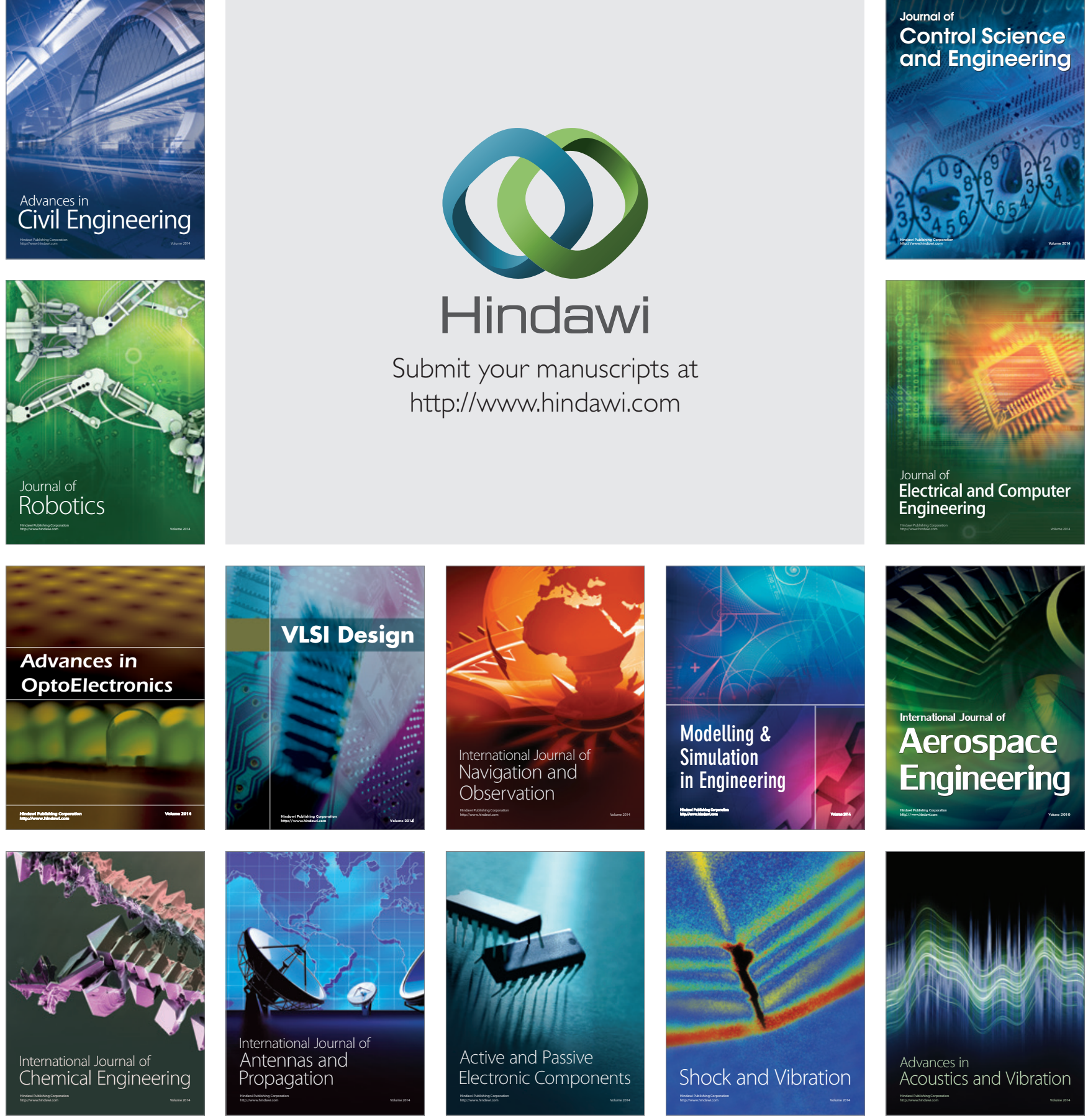